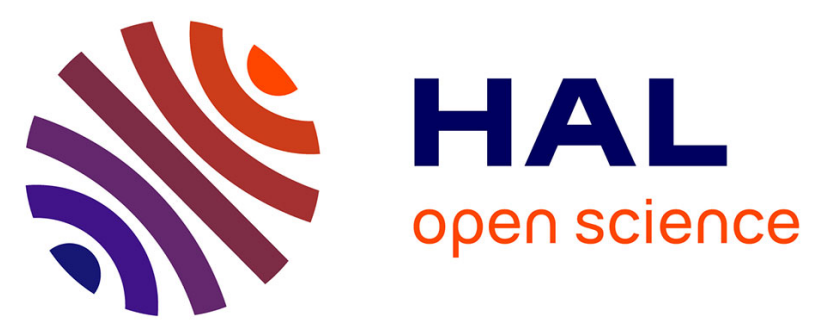

\title{
Impact of n-3 Docosapentaenoic Acid Supplementation on Fatty Acid Composition in Rat Differs Depending upon Tissues and Is Influenced by the Presence of Dairy Lipids in the Diet
}

Gaëtan Drouin, Étienne Guillocheau, Daniel D. Catheline, Charlotte Baudry, Pascale Le Ruyet, Vincent V. Rioux, Philippe P. Legrand

\section{To cite this version:}

Gaëtan Drouin, Étienne Guillocheau, Daniel D. Catheline, Charlotte Baudry, Pascale Le Ruyet, et al.. Impact of n-3 Docosapentaenoic Acid Supplementation on Fatty Acid Composition in Rat Differs Depending upon Tissues and Is Influenced by the Presence of Dairy Lipids in the Diet. Journal of Agricultural and Food Chemistry, 2018, 66 (38), pp.9976 - 9988. 10.1021/acs.jafc.8b03069 . hal01884792

\section{HAL Id: hal-01884792}

\section{https://institut-agro-rennes-angers.hal.science/hal-01884792}

Submitted on 2 Oct 2018

HAL is a multi-disciplinary open access archive for the deposit and dissemination of scientific research documents, whether they are published or not. The documents may come from teaching and research institutions in France or abroad, or from public or private research centers.
L'archive ouverte pluridisciplinaire HAL, est destinée au dépôt et à la diffusion de documents scientifiques de niveau recherche, publiés ou non, émanant des établissements d'enseignement et de recherche français ou étrangers, des laboratoires publics ou privés. 


\section{Impact of n-3 Docosapentaenoic Acid Supplementation on Fatty Acid Composition in Rat Differs Depending upon Tissues and Is Influenced by the Presence of Dairy Lipids in the Diet}

Gaetan Drouin, ${ }^{\dagger}$ Etienne Guillocheau, ${ }^{\dagger}{ }^{\circledR}$ Daniel Catheline, ${ }^{\dagger}$ Charlotte Baudry, ${ }^{\ddagger}$ Pascale Le Ruyet, ${ }^{\dagger}$ Vincent Rioux, ${ }^{\dagger}$ and Philippe Legrand ${ }^{*}+\dagger$

${ }^{\dagger}$ Laboratory of Biochemistry and Human Nutrition, Agrocampus Ouest, Rennes F-35000, France

${ }^{\ddagger}$ Lactalis, R\&D, Retiers F-35240, France

Supporting Information

ABSTRACT: The $n-3$ docosapentaenoic acid (n-3 DPA) could be a novel source of $n-3$ long-chain polyunsaturated fatty acids (LCPUFA) with beneficial physiological effects. Following the supplementation of $0.5 \%$ purified n-3 DPA for 3 weeks from weaning, the $\mathrm{n}-3$ DPA content increased in one-half of the 18 studied tissues (from $+50 \%$ to $+110 \%, p<0.05$ ) and mostly affected the spleen, lung, heart, liver, and bone marrow. The n-3 DPA was slightly converted into DHA $(+20 \%$ in affected tissues, $p<0.05)$ and mostly retroconverted into EPA (35-46\% of n-3 DPA intake in liver and kidney) showing an increased content of these LCPUFA in specific tissues. The partial incorporation of dairy lipids in the diet for 6 weeks increased overall $n$ 3 PUFA status and brain DHA status. Furthermore, the n-3 DPA supplementation and dairy lipids had an additive effect on the increase of n-3 PUFA tissue contents. Moreover, n-3 DPA supplementation decreased plasma cholesterol.

KEYWORDS: polyunsaturated fatty acid (PUFA) metabolism, dairy lipids, cholesterol, eicosapentaenoic acid (EPA),

tissue composition

\section{INTRODUCTION}

The $n-3$ docosapentaenoic acid (n-3 DPA) is a member of the n-3 long-chain polyunsaturated fatty acid (PUFA) essential family. ${ }^{1}$ It is also an intermediate between eicosapentaenoic acid (EPA) and docosahexaenoic acid (DHA) in the n-3 PUFA conversion pathway from $\alpha$-linolenic acid (ALA). ${ }^{2}$ Many studies have shown the beneficial role of n-3 PUFA in the reduction of cardiovascular risk, metabolic syndrome, cancer, and inflammation. ${ }^{3-5}$ Unfortunately, the n-3 PUFA conversion pathway is limited in humans as in rodents. ${ }^{6}$ Indeed, the conversion from ALA occurs through a sequence of desaturations and elongations including two enzymes considered as limiting steps: the $\Delta-6$ desaturase and the elongase-2. ${ }^{7}$ Moreover, the main part of ALA intake is lower than the dietary recommendations in humans ${ }^{8}$ and is deposited in adipose tissues or catabolized by mitochondrial $\beta$ oxidation. ${ }^{9}$ Furthermore, direct supplementation with the different precursors of DHA, $\alpha$-linolenic acid (C18:3 n-3, ALA $),{ }^{10}$ stearidonic acid (C18:4 n-3), ${ }^{11}$ or EPA, ${ }^{12}$ showed an increase in EPA and n-3 DPA, whereas the DHA status remained stable or was only slightly increased.

n-3 DPA was described as a potential reservoir of n-3 PUFA. ${ }^{13}$ Indeed, n-3 DPA could be interesting both for its potential capacity to be converted into DHA or retroconverted into EPA and for its potential physiological effects. ${ }^{14-16}$ This fatty acid (FA) has been poorly studied especially in vivo as compared to EPA and DHA, probably due to its relative lack of commercial availability in high quantity and purity. ${ }^{17}$ Consequently, the whole-body assimilation and FA metabolism of n-3 DPA has not been addressed yet.
Nutritional sources of n-3 DPA are mainly sea products, meat including giblets, n-3 enriched food, and dairy products. ${ }^{18}$ Thereby, the n-3 DPA intake is mainly in the form of phospholipids and triglycerides in the food or in ethyl ester form in food supplement. ${ }^{19}$ Moreover, n-3 PUFA bioavailability seems better when they are consumed in complex matrix than as supplement form. ${ }^{20}$ This raises the question of the lipid mixture in which n-3 DPA is ingested to modulate its tissue delivery and metabolism after digestion and absorption.

Indeed, including dairy lipids in the diet increased the n-3 PUFA content, as compared to a lipid mixture of vegetable oils, in different nutritional and physiological conditions. ${ }^{21-24}$ More specifically, the DHA level was increased in the brain and the retina, while n-3 DPA was increased in some tissues like the heart, the liver, and red blood cells (RBC). ${ }^{24}$ These authors also showed that n-3 DPA content in RBC, which increased with dairy lipids diet, could act as a predictor of brain DHA status. ${ }^{25}$ Moreover, dairy products provide $9 \%$ of the n-3 DPA intake in Canadian pregnant and lactating women and 6\% in children. ${ }^{17}$ However, the absolute intake remains low in Europe and is about $12-80 \mathrm{mg} /$ day in human adults and about $30-40 \mathrm{mg} /$ day in children. ${ }^{26}$ Nevertheless, dairy lipids could be a good lipid mixture for the assimilation of dietary n-3 DPA and for increasing the n-3 PUFA status.

The present study contains two experiments with the aim of showing whether the dietary n-3 DPA is assimilated within the

Received: June 12, 2018

Revised: July 22, 2018

Accepted: July 29, 2018

Published: July 29, 2018 


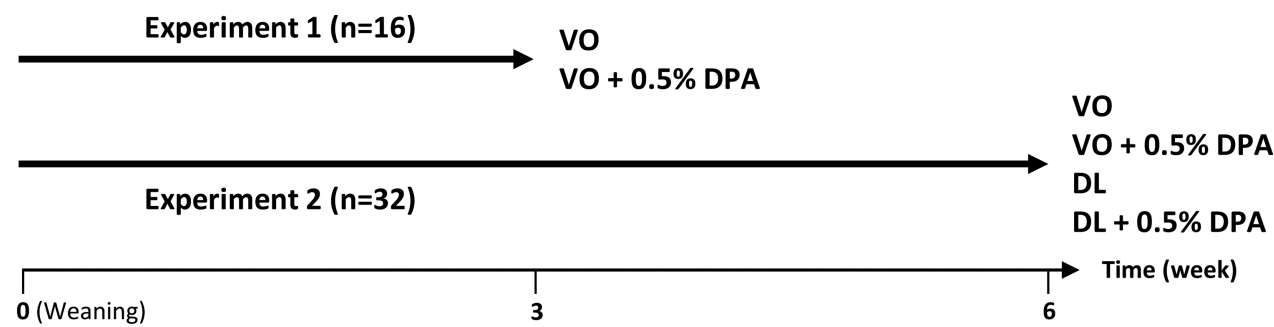

Figure 1. Experimental procedures of the experiments 1 and 2. In experiment 1 , male rats received for 3 weeks from weaning a control diet with a lipid source composed of a vegetable oil blend not supplemented (VO) or supplemented with $0.5 \% \mathrm{n}-3$ docosapentaenoic acid (VO+DPA). In experiment 2, rats fed for 6 weeks from weaning with the same VO and VO+DPA diets as in experiment 1 or with diet containing a lipid source composed with a vegetable oil blend and dairy lipids not supplemented (DL) or supplemented with $0.5 \% \mathrm{n}-3$ DPA (DL+DPA).

tissues, and whether n-3 DPA is converted into DHA or retroconverted into EPA and could increase the overall n-3 PUFA tissue status depending on the lipid mixture inside which it was included. In experiment 1 , we studied the whole body assimilation and the overall FA metabolism of n-3 DPA, and we investigated which tissues were the most impacted by the n-3 DPA dietary supplementation for 3 weeks as ethyl ester. In experiment 2, we studied if n-3 DPA supplementation and the addition of dairy lipids in the diet for 6 weeks could have a complementary effect to increase n-3 PUFA tissue status.

\section{MATERIALS AND METHODS}

2.1. Chemicals. Solvents and chemicals were obtained from Thermo Scientific (Élancourt, France), VWR (Fontenay-sous-Bois, France), or Sigma (Saint-Quentin-Fallavier, France). Polaris (Quimper, France) graciously provided high n-3 PUFA marine oil (Omegavie 4020 EE Qualitysilver). Anhydrous milk fat and oleic sunflower oil were provided by Lactalis group (Retiers, France).

2.2. Animals. This study is composed of two experiments (Figure 1 ). In experiment 1,32 rats ( $n=8$ /group) were fed from weaning for 3 weeks with VO diet supplemented or not supplemented with $0.5 \%$ n-3 DPA (VO+DPA). In experiment 2,32 rats $(n=8$ /group) were fed from weaning for 6 weeks with $\mathrm{VO}$ or DL diets not supplemented or supplemented with $0.5 \% \mathrm{n}-3$ DPA (VO+DPA and DL+DPA). For both experiments, Sprague-Dawley male rats (mean body weight 50 $\pm 1 \mathrm{~g}, 3$ weeks old at beginning of the experiment) (Janvier Laboratories, Le Genest-Saint-Isle, France) were randomly assigned into the groups and were housed four animals by cage with free access to water and food on a $12 \mathrm{~h}$ light-dark cycle, maintained at a temperature of $21 \pm 2{ }^{\circ} \mathrm{C}$ and at a hygrometry of $50 \% \pm 10 \%$. Body weight, food, and water intakes were measured two times a week. Sprague-Dawley rats were chosen considering their FA metabolism close to human, the nonconsanguinity of Sprague-Dawley rats ensures heterogeneity of the populations, the animal is large enough to obtain large enough samples for analysis purposes, and it is small enough to consume enough DPA to allow nutritional study. Only male animals were chosen to overcome the influence of estrogen and the menstrual cycle on fatty acid and lipid metabolisms in female rats. $^{27}$

All experiments were performed in accordance with the European Union Guidelines for Animal Care and Use (2010/63/CEE). The experimental procedures (no. APAFIS\#1389-2015080411586889 v4 and no. APAFIS\#5139-201605121200996 v1) were approved by the French Animal Care Committee (Rennes, approval number A3523838) and the Ministry of Higher Education, Research and Innovation, in compliance with recommendations of the 2013-118 French directive for animal experimentation. The number of animal by group was chosen considering a power calculation based on tissue FA composition fold-change in PUFA after a dietary supplementation with $0.5 \%$ DHA in similar experimental conditions. ${ }^{24}$

At the end of the experiments, fasted rats were anesthetized with an intraperitoneal injection of sodic pentobarbital $(140 \mathrm{mg} / \mathrm{kg}$ of body weight) (Euthasol Vet, France). Blood samples were collected by cardiac punctures into lithium heparin-treated vacutainers (Dominique Dutscher, Brumath, France), and plasma was separated from blood cells by centrifugation $(3000 \mathrm{~g}, 20 \mathrm{~min}$, room temp $)$ and stored at $-80{ }^{\circ} \mathrm{C}$. After removing the peripheral blood mononucleated cells layer, red blood cells (RBC) were mixed, weighted, and stored at +4 ${ }^{\circ} \mathrm{C}$ before lipid extraction. Whole eyes were removed by section of the optic nerve and then stored in $4 \%$ formaldehyde in PBS at $4{ }^{\circ} \mathrm{C}$ for at least 1 week; the retina was dissected by removing muscle membrane, optic nerve, cornea, lens, and vitreous body, and then washed in PBS. Tissues were removed, washed with PBS, weighted, and around 200 $\mathrm{mg}$ of each tissue was stored in dimethoxymethane/methanol (4/1, v/ v) at $-20{ }^{\circ} \mathrm{C}$. The rest of the organs were snap-frozen in liquid nitrogen and stored at $-80{ }^{\circ} \mathrm{C}$. In experiment 1,18 tissues were collected and analyzed to realize the whole-body impact of n-3 DPA on fatty acid composition in tissue: bone marrow, brain, epididymal adipose tissue, heart, jejunum, kidney, liver, lung, muscle, pancreas, plasma, red blood cells, retina, subcutaneous adipose tissue, skin, spleen, stomach, and testis. In experiment 2 , the tissues most impacted by n-3 DPA supplementation were collected as well as the brain. In experiment 2, we also studied the FA composition of the $\mathrm{RBC}$ and the brain, particularly interesting for the potential impact of dairy lipids on these tissues.

2.3. Diets. Four different lipid blends were prepared from a combination of natural fat sources (Table 1). Lipid blends were composed of a blend of vegetable oils (VO) or a blend of vegetable oils and dairy lipids (DL), not supplemented or supplemented with $0.5 \% \mathrm{n}-3 \mathrm{DPA}(\mathrm{w} / \mathrm{w}, 0.1 \%$ of total energy) (VO+DPA and DL +DPA). Lipid blends were made with particular attention to ALA and linoleic acid (LA) levels, with an LA/ALA ratio around 5 as nutritionally recommended in humans in France. ${ }^{28}$ The addition of short- and medium-chain fatty acids (SMCFA) with the introduction of dairy lipids was adjusted with oleic acid. FA composition of lipid blends composing the diets was analyzed by GC-MS after Folch extraction of diets and derivation as described above in section 2.5. Total sterols were measured in DL and VL blends by Liebermann method to estimate the cholesterol intake of animals as described previously. $^{24}$

All of the diet contained $10 \%$ (w/w, 21\% of total energy) of lipid blend and $90 \%(\mathrm{w} / \mathrm{w})$ of a lipid-free base. The lipid-free base was prepared at the Unité de Production d'Aliments Expérimentaux (UPAE, INRA, Jouy-en-Josas, France). The lipid-free base contained for $1 \mathrm{~kg}$ of diet: $220.0 \mathrm{~g}$ of HCl-casein, $1.5 \mathrm{~g}$ of DL-methionine, $402.3 \mathrm{~g}$ of corn starch, $201.2 \mathrm{~g}$ of sucrose, $20.0 \mathrm{~g}$ of cellulose, $45.0 \mathrm{~g}$ of mineral mix 102, and $10.0 \mathrm{~g}$ of vitamin mix 102 . Next, $100.0 \mathrm{~g}$ of fat $/ \mathrm{kg}(21 \%$ of total energy) of diet from the lipid blends was added in our laboratory.

To prepare the rat diet, the lipid-free base and the lipid blend were mixed then sifted twice, $13 \%$ water was added $(\mathrm{w} / \mathrm{w})$, and then the mixture was homogenized and shaped as croquettes. The rat diets were sealed in an airtight package and frozen at $-20{ }^{\circ} \mathrm{C}$, as all diets were prepared at the beginning of the study. During the experiments, rat diets were thawed at $+4{ }^{\circ} \mathrm{C} 24 \mathrm{~h}$ before being given to animals. The n-3 DPA-EE possible peroxidation was controlled by TBARS test on diets, ${ }^{24}$ and malondialdehyde was not detected in diets at the 
Table 1. Oil Mixtures and Fatty Acid Composition of the Four Experimental Diets

\begin{tabular}{|c|c|c|c|c|}
\hline diets & $\mathrm{VO}$ & $\mathrm{VO}+\mathrm{DPA}$ & $\mathrm{DL}$ & $\mathrm{DL}+\mathrm{DPA}$ \\
\hline \multicolumn{5}{|c|}{ Oil Mixture Composing the Lipid Blends (g/100g) } \\
\hline butter fat & & & 50.0 & 49.7 \\
\hline palm oil & 35.0 & 34.8 & & \\
\hline high oleic sunflower & 42.0 & 41.8 & 22.0 & 21.9 \\
\hline sunflower oil & & & 7.00 & 7.00 \\
\hline rapeseed oil & 23.0 & 22.9 & 21.0 & 20.9 \\
\hline DPA-EE ${ }^{a}$ & & 0.50 & & 0.50 \\
\hline
\end{tabular}

Fatty Acids Composition of the Lipid Blends (\%)

$\begin{array}{ccccc}\text { saturated FA } & 22.4 & 22.2 & 36.5 & 36.6 \\ \text { SMCFA }^{b} & & & 3.40 & 3.40 \\ \text { branched chain FA }^{c} & & & 0.90 & 0.90 \\ \text { C14:0 } & 0.30 & 0.30 & 5.60 & 5.60 \\ \text { C16:0 } & 18.2 & 18.1 & 18.2 & 18.1 \\ \text { C18:0 } & 3.30 & 3.30 & 6.80 & 6.80 \\ \text { odd FA } & & & 0.80 & 0.80 \\ \text { monounsaturated FA } & 64.0 & 63.7 & 48.0 & 47.7 \\ \text { C18:1 n-9 } & 61.8 & 61.8 & 43.1 & 42.9 \\ \text { polyunsaturated FA } & 13.6 & 14.1 & 15.5 & 15.7 \\ \text { C18:2 n-6 (LA) } & 11.4 & 11.4 & 12.4 & 12.2 \\ \text { C18:3 n-3 (ALA) } & 2.20 & 2.20 & 2.30 & 2.30 \\ \text { C22:5 n-3 (DPA) } & & 0.50 & \operatorname{Tr}^{e} & 0.50 \\ \text { others } & & & 0.70 & 0.70 \\ \text { LA/ALA ratio } & 5.20 & 5.20 & 5.40 & 5.30\end{array}$

${ }^{a}$ Ethyl esters purified by liquid chromatography. ${ }^{b}$ Short- and medium-

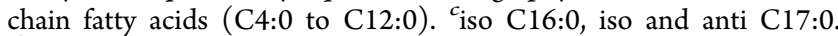
${ }^{d}$ Saturated FA with an impair number of carbon. ${ }^{e}$ Tr: trace $(<0.01 \%)$. FA: fatty acids. EPA and DHA were not detected in all diets.

beginning and at the end of the study. The diets were isoenergetic ( $3650 \mathrm{kcal} / \mathrm{kg}$ of diet) and isolipidic ( $21 \%$ of total energy).

2.4. n-3 Ethyl Docosapentaenoate (DPA-EE) Purification. The n-3 DPA-EE with purity $>99 \%$ of total detected FA was obtained from a high n-3 PUFA marine oil (Omegavie 4020EE Qualitysilver, Polaris). The purification was performed by liquid chromatography in seven steps with a puriFlash4250 system (Interchim, Montluçon, France) with a Chromabond flash column (RS $330 \mathrm{C} 18 \mathrm{ec}$, porosity $45 \mu \mathrm{m}$, diameter $60 \mathrm{~mm}$, length $200 \mathrm{~mm}$, Macherey Nagel, Hoerdt, France) followed by a Puriflash flash column (PF-15C18 HP-F0330, granulometry $15 \mu \mathrm{m}$, diameter $60 \mathrm{~mm}$, length $226 \mathrm{~mm}$, Interchim) and coupled with an UV detector. For the first two steps, the elution was performed at room temperature in an isocratic mode of methanol/water $(99 / 1, \mathrm{v} / \mathrm{v})$ with a constant flow of $120 \mathrm{~mL} / \mathrm{min}$. The fraction corresponding to n-3 DPA-EE was collected and was evaporated with a rotatory evaporator, then analyzed by gas chromatography-mass spectrometry (GC-MS) to control purity and efficiency. The collected fraction of step 2 then was reinjected with an elution of methanol/water $(98 / 2, \mathrm{v} / \mathrm{v})$ in the same conditions (step 3). This purification cycle was repeated three more times (steps $4-6)$ to gradually increase the purity in n-3 DPA-EE of the fraction of interest until $95 \%$.

The fraction of step 6 was injected in the same conditions in an Interchrom preparative column (Uptisphere strategy C18-HQ, granulometry $5 \mu \mathrm{m}$, diameter $50 \mathrm{~mm}$, length $250 \mathrm{~mm}$, Interchim) with an isocratic mode of methanol/water $(98 / 2, \mathrm{v} / \mathrm{v})($ step 7$)$. The fraction corresponding to the n-3 DPA-EE peak was collected and pooled to obtain n-3 DPA-EE > 99\% purity of total detected FA (see Supporting Information A, Figure S1). The n-3 DPA-EE possible peroxidation was controlled by a TBARS test on n-3 DPA-EE oil. ${ }^{24}$ Malondialdehyde (TBARS) was not detected in the n-3 DPA-EE final purified fraction.

2.5. Lipid Extraction and Fatty Acid Composition. Lipids were extracted twice from tissues with 20 volumes dimethoxy- methane/methanol $(4 / 1, \mathrm{v} / \mathrm{v})$ after homogenization with an UltraTurrax. RBC lipid membranes and plasma were extracted twice with hexane/isopropanol $(3 / 2, \mathrm{v} / \mathrm{v})$ after acidification with $\mathrm{HCl} 3 \mathrm{M}$, as previously described. ${ }^{24}$ Brain phospholipids were separated from total lipids on preparative thin-layer chromatography (TLC) using silica gel H (Merck Millipore, Darmstadt, Germany) plates impregnated with a mixture of hexane/diethyl ether/acetic acid (85/15/1, v/v/v). Total lipids and phospholipids were saponified by $1 \mathrm{~mL}$ of $0.5 \mathrm{M} \mathrm{NaOH}$ in methanol at $70^{\circ} \mathrm{C}$ for $30 \mathrm{~min}$ and then methylated with $1 \mathrm{~mL}$ of $\mathrm{BF}_{3}$ $\left(12 \%\right.$ in methanol) at $70{ }^{\circ} \mathrm{C}$ for $30 \mathrm{~min}$. Fatty acid methyl esters were extracted twice with pentane, washed twice with $\mathrm{NaCl} 0.9 \%$, and were taken up in hexane. Fatty acid methyl esters from brain phospholipids were purified by another step of TLC with a mixture of hexane/ diethyl ether $(80 / 20, \mathrm{v} / \mathrm{v})$, extracted a first time by a mixture of methanol/hexane/ $\mathrm{NaCl} 0.9 \%(3 / 4 / 3, \mathrm{v} / \mathrm{v} / \mathrm{v})$, then extracted a second time with 4 volumes of hexane, washed with $\mathrm{NaCl} 0.9 \%$, and were taken up in hexane. ${ }^{29}$

GC--MS analysis was performed using an Agilent 7890A (Agilent technologies, Santa Clara, CA) with a bonded silica capillary column (BPX 70, $60 \mathrm{~m} \times 0.25 \mathrm{~mm}$; SGE, Melbourne, Australia) containing a polar stationary phase of $70 \%$ cyanopropyl polysilphenylene-siloxane $(0.25 \mu \mathrm{m}$ film thickness). Helium was used as the carrier gas (average velocity $36 \mathrm{~cm} / \mathrm{s}$ ). The column temperature program started at 150 ${ }^{\circ} \mathrm{C}$ and gradually increased at $4{ }^{\circ} \mathrm{C} / \mathrm{min}$ to $250{ }^{\circ} \mathrm{C}$, and held at 250 ${ }^{\circ} \mathrm{C}$ for $10 \mathrm{~min}$. Mass spectra were recorded with an Agilent Technologies 5975C inert MSD with triple axis detector. The mass spectrometer was operated under electron impact ionization conditions (electron energy $70 \mathrm{eV}$, source temperature $230{ }^{\circ} \mathrm{C}$ ). Data were obtained in the full scan mode with a mass range of $\mathrm{m} / \mathrm{z}$ 50-550 atomic mass units (amu), using the MSD Chemstation software E.02.02.14.31. Identification of the FA methyl esters was based upon retention times obtained for methyl ester of authentic standards, when available. The National Institute of Standards and Technology database v2.0 was also sometimes used to identify unknown FA. All identified FA with a signal/noise $>10$ were considered in the analysis of the proportions, and FA identified with a signal/noise between 3 and 10 was marked as trace.

The apparent retroconversion of n-3 DPA into EPA in the liver was estimated as percentage using the following formula:

$$
\frac{\Delta \mathrm{EPA}_{(\text {supplemented-control })}}{\Delta \mathrm{EPA}+\mathrm{DPA}_{(\text {supplemented-control })}} \times 100
$$

2.6. Biochemical Parameters of Plasma. In experiment 2, total cholesterol (cholesterol CHOL, Randox Laboratories, Crumlin, UK), high-density lipoprotein cholesterol (HDL-cholesterol) (HDLCHOL, Randox Laboratories), and free-cholesterol (free-CHOL-FS, DiaSys, Holzheim, Germany) concentrations were assayed with commercial enzymatic kits according to the manufacturer's instructions on heparinized plasma in triplicate. Non-HDL cholesterol was calculated by the difference between total cholesterol and HDLcholesterol. Cholesterol esters concentration was calculated by the difference between total cholesterol and free-cholesterol concentrations.

2.7. Statistical Analysis. The aim of experiment 1 was to study the impact of n-3 DPA supplementation during 3 weeks on PUFA metabolism. FA compositions of tissues of $\mathrm{VO}$ and $\mathrm{VO}+\mathrm{DPA}$ groups were compared by the adjusted multiple Student $t$ test $(\alpha=0.05)$. To identify the most impacted tissues by the DPA supplementation, orthogonal least-squares discriminant analysis (OPLS-DA) then was performed. ${ }^{30}$ As FA compositions were handled as the percentage of total identified FA, the data were first centered log-ratio transformed. The data then were centered and scaled, because a wide range of values for FA proportions were found. ${ }^{31}$

The model was validated by cross-validation ANOVA $(\alpha=0.05)$. The significant variables were selected using a variable importance in projection coefficient $>1$ and the jackknife CI error bars on S-plot. ${ }^{32}$ To rank the most impacted tissues and the most impacted FA, we used a score based on the number of significant variables and on the 

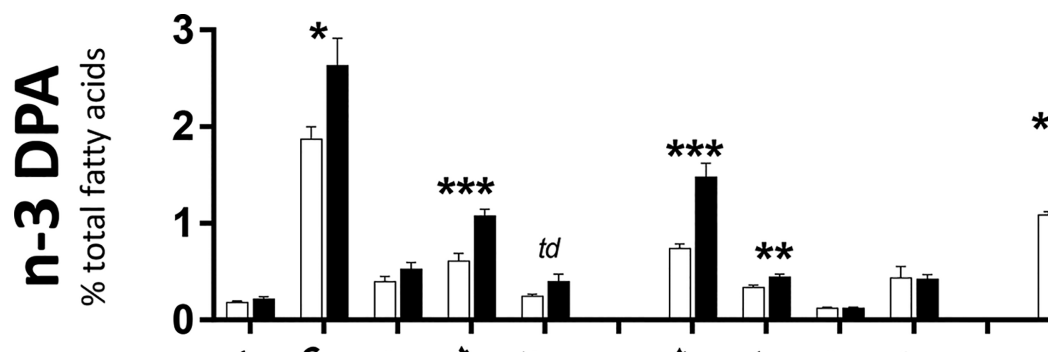

$\square$ VO diet

VO + n-3 DPA diet

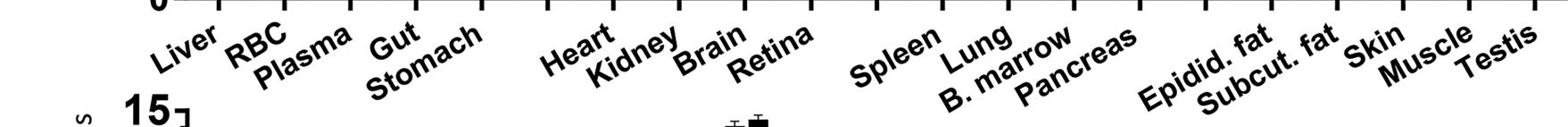

$\frac{1}{\substack{\frac{1}{0} \\ \frac{0}{0}}}$
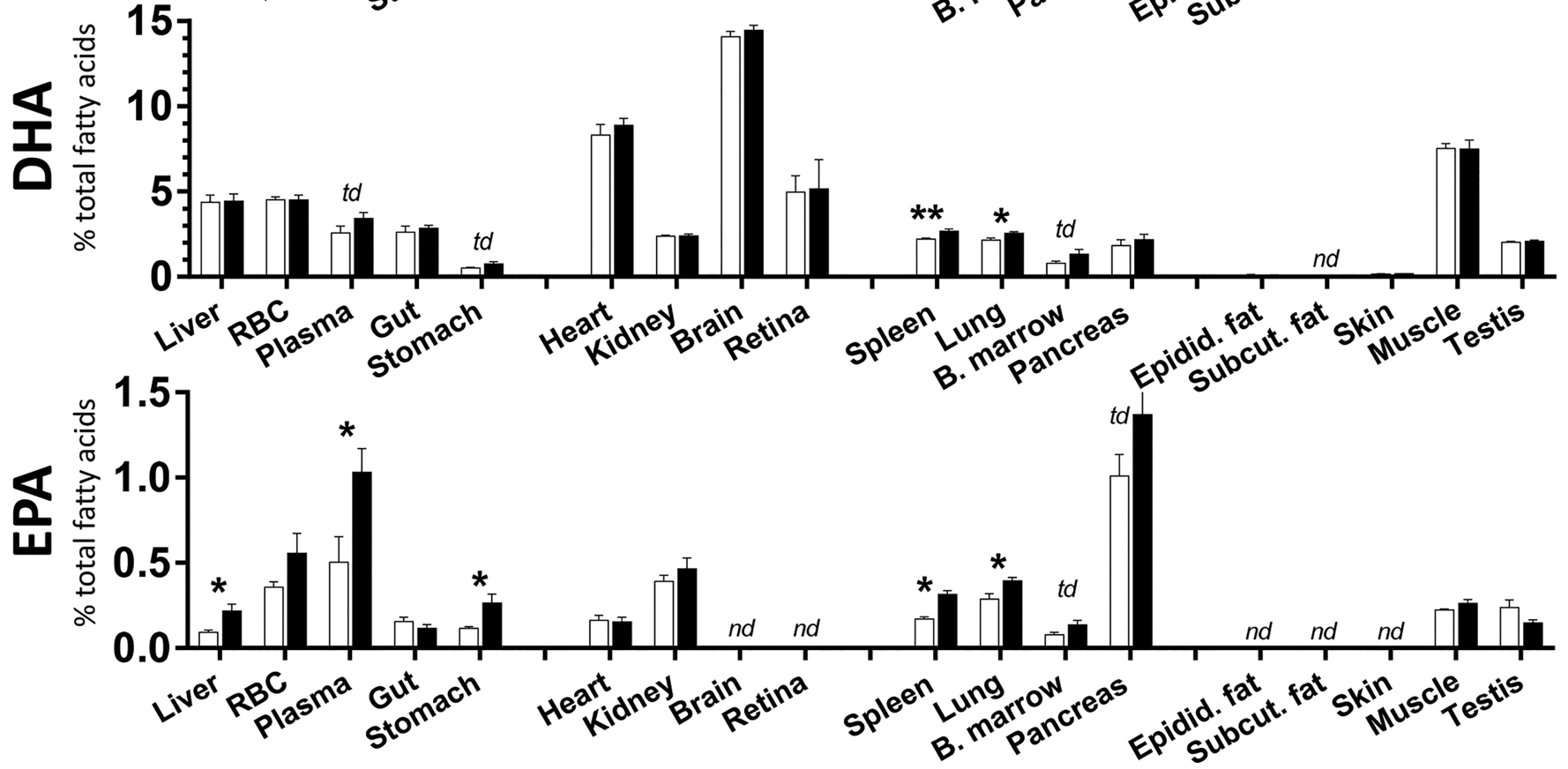

Figure 2. Fatty acid composition of tissues in n-3 docosapentaenoic acid (DPA), docosahexaenoic acid (DHA), and eicosapentaenoic acid (EPA) of rats fed with a control VO diet (white) or a $0.5 \%$ n-3 DPA-supplemented VO diet (black) during 3 weeks. Results were expressed as mean \pm SEM. Significance between groups was evaluated by multiple Student $t$ test $(* p<0.05 ; * * p<0.01 ; * * p<0.001 ;$ td $0.1<p<0.05)$. Complete fatty acids profiles of all tissues are available in Supporting Information B, Tables 1-6. nd: not detected.

variable coefficient of the first component calculated for each tissue or for each FA.

The aim of experiment 2 was to compare the combined effect of $n$ 3 DPA supplementation with two lipid mixtures after 6 weeks of diet. FA composition of tissues, plasma assays, and organs weights of $\mathrm{VO}$, $\mathrm{VO}+\mathrm{DPA}, \mathrm{DL}$, and DL+DPA groups were compared with two-way ANOVA. The major aims were to study the effects of DPA supplementation (VO and DL vs VO+DPA and DL+DPA) and lipid mixture (VO and $\mathrm{VO}+\mathrm{DPA}$ vs $\mathrm{DL}$ and $\mathrm{DL}+\mathrm{DPA}$ ) on FA composition of tissues, and the interaction between both effects. Type-II ANOVA was used when the interaction was nonsignificant, and type-III ANOVA was used when the interaction was significant. Body weight and food consumption were analyzed with the same model for repeated measures; whenever the model was significant, multiple comparisons according to Tukey procedure adjusted with false discovery rate method (fdr) were performed. Prior to analysis, normality of the data of the residuals was graphically assessed and homoscedasticity was supposed verified. For all procedures, a $p$-value $<0.05$ was considered as significant. All data were reported as mean \pm SEM.

Redundancy analysis (RDA) was used in experiment 2 to study the global interaction between the n-3 DPA supplementation and the lipid mixture. RDA corresponds to ANOVA in a multivariate framework. $^{33}$ Constraints (i.e., factors) were the n-3 DPA supplementation effect, the lipid mixture effect, and the interaction between both factors. RDA was performed on FA composition of the four most impacted tissues by the n-3 DPA supplementation in experiment 1 . As FA compositions were presented as the percentage of total detected FA, and that the FA proportion took place in a large range of values, the data were transformed by centering log-ratio, then by centering-scaling. ${ }^{31} \mathrm{~A}$ permutation test was used to assess the significance of all constraints. This test was followed by pairwise comparisons using factor fitting to an ordination adjusted with fdr method to assess the significance between the four diets. FA explaining most of the variability between the two effects was chosen by considering the test of Pearson correlation coefficient between FA data and individual scores, and a Pearson correlation coefficient $R^{2}>$ 0.5 .

Univariate analysis and redundancy analysis were realized using $\mathrm{R}$ software v3.4.2 and R packages car v2.1.5, RVAideMemoire v0.9.68, vegan v2.4.4, and chemometrics v0.1. OPLS-DA was performed with Simca software v14.1 (Umetrics, Umeå, Sweden).

\section{RESULTS}

The aim of experiment 1 was to study the whole-body assimilation and FA metabolism of the n-3 DPA after 3 weeks of dietary n-3 DPA supplementation, and it focused on 18 tissues. The complete FA compositions of tissues from experiment 1 are presented in Supporting Information B, Tables S1-S6.

3.1. Experiment 1: Impact of n-3 DPA Supplementation on Fatty Acid Composition in Tissues after 3 weeks 


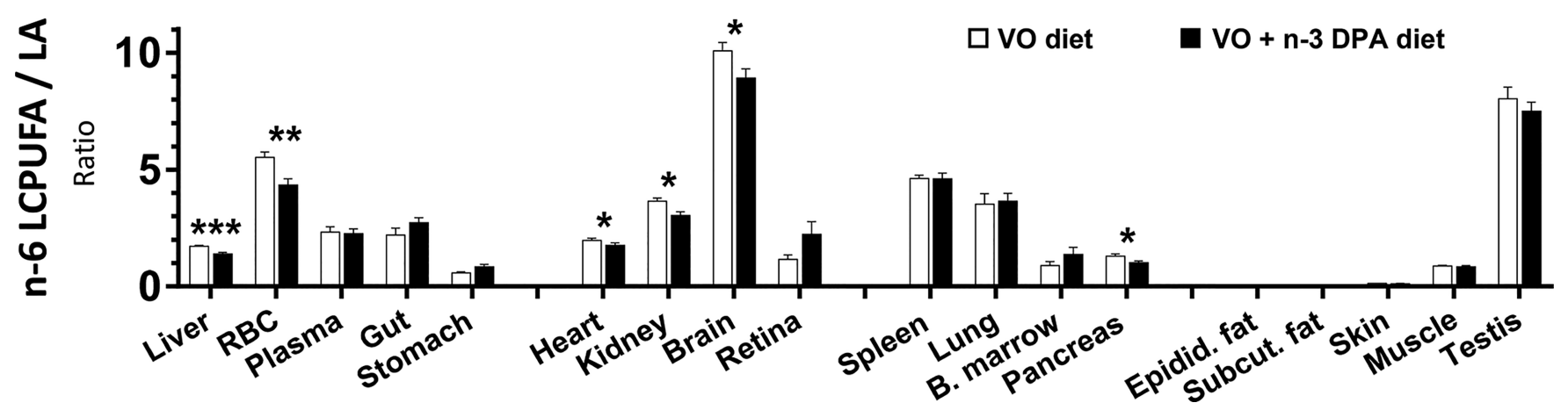

Figure 3. Ratio n-6 LCPUFA/LA from fatty acid composition of tissues of rats fed with a control VO diet (white) or a $0.5 \%$ n-3 DPAsupplemented VO diet (black) during 3 weeks. Results were expressed as mean \pm SEM. Significance between groups was evaluated by multiple Student $t$ test $\left(* p<0.05 ; * *_{p}<0.01 ; * * p<0.001\right)$. Complete fatty acids profiles of all tissues are available in Supporting Information B, Tables $1-6$.

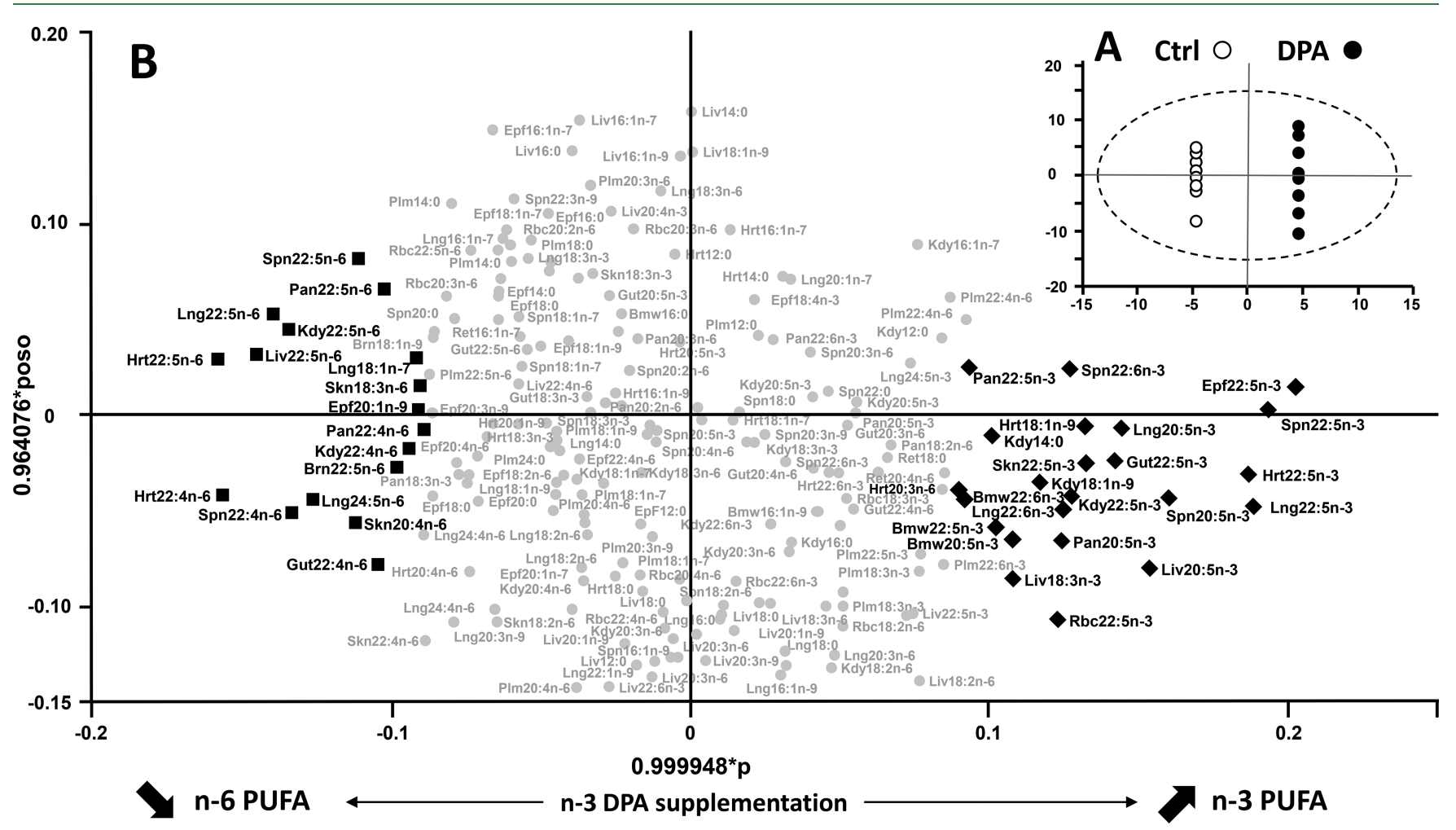

Figure 4. OPLS-DA model of all fatty acids of the studied tissues of rats fed with a control diet (Ctrl) or a $0.5 \%$ n-3 DPA-supplemented diet (DPA) for 3 weeks. (A) OPLS-DA score plot. Each rat is represented by a point (i.e., 16 points), falling into either CTRL or DPA. A significant discrimination between both groups is obtained along with the horizontal axis (CV-ANOVA, $p<0.05)$. $R^{2}$ (explaining class variance) and $Q^{2}$ (explaining class prediction) values were 0.986 and 0.776 , respectively. (B) OPLS-DA loading plot. Each fatty acid (or variable) from one tissue is represented by a point. The horizontal axis is significantly characterized by colored fatty acids, according to their variable importance in projection coefficient $(>1)$ and their jack-knife CI errors bars. In straight relationship with the score plot, rats fed the n-3 DPA diet are associated with higher n-3 PUFA status and lower n-6 PUFA status as compared to Ctrl. The converse occurs for the rats fed the Ctrl diet. To make it clearer, some nonsignificant variables were randomly removed from the loading plot. Supporting Information B, Tables 1-6 gathers all fatty acids considered in the OPLS-DA model. Bmw, bone marrow; Brn, brain; Epf, epididymal adipose tissue; Hrt, heart; Kdy, kidney; Liv, liver; Lng, lung; Mus, muscle; Pan, pancreas; Plm, plasma; Rbc, red blood cells; Ret, retina; Scf, subcutaneous adipose tissue; Skn, skin; Spn, spleen; Stc, stomach.

of Diet. At the end of experiment 1, body weight gain, organ weight, and food intake did not differ significantly between groups (see Supporting Information A, Figure S2 and Table S1).

\subsection{1. n-3 DPA Supplementation Increased n-3 PUFA and} Decreased n-6 PUFA. Following the n-3 DPA supplementation, the n-3 DPA content ranked from $0.1 \%$ in epididymal adipose tissue to $2.6 \%$ in red blood cells, and it was not detected in testis and subcutaneous adipose tissue (Figure 2).
More precisely, the proportion of $n-3$ DPA increased significantly in the heart (2.1-fold), the lung (1.8-fold), the gut (1.8-fold), the spleen (1.6-fold), the bone marrow (1.5fold), the RBC (1.4-fold), the kidney (1.3-fold), and the skin (1.5-fold) in the DPA-supplemented group. The n-3 DPA content tended to increase in the stomach $(2.0$-fold, $p=0.072)$ and the pancreas (1.2-fold, $p=0.083)$. In the epididymal adipose tissue, the n-3 DPA was detected only in the n-3 DPA supplemented group. By contrast, n-3 DPA levels were not 
Table 2. n-3 PUFA Tissue Contents ${ }^{a}$

\begin{tabular}{|c|c|c|c|c|c|c|c|c|c|c|c|}
\hline \multirow[b]{2}{*}{ liver } & \multirow{2}{*}{$\begin{array}{l}\text { FA \% } \\
\text { ALA }\end{array}$} & \multicolumn{2}{|c|}{$\mathrm{VO}$} & \multicolumn{2}{|c|}{$\mathrm{VO}+\mathrm{DPA}$} & \multicolumn{2}{|c|}{$\mathrm{DL}$} & \multicolumn{2}{|c|}{$\mathrm{DL}+\mathrm{DPA}$} & \multirow[t]{2}{*}{ DPA } & \multirow{2}{*}{$\begin{array}{l}\mathrm{LM} \\
* *\end{array}$} \\
\hline & & $0.48 \mathrm{a}$ & \pm 0.07 & $0.50 \mathrm{a}$ & \pm 0.07 & $0.63 \mathrm{ab}$ & \pm 0.06 & $0.69 \mathrm{~b}$ & \pm 0.05 & & \\
\hline & EPA & $0.14 \mathrm{~A}$ & \pm 0.01 & $0.16 \mathrm{~A}$ & \pm 0.02 & $0.33 \mathrm{~B}$ & \pm 0.04 & $0.67 \mathrm{C}$ & \pm 0.07 & $* * *$ & $* *$ \\
\hline & n-3 DPA & $0.37 \mathrm{~A}$ & \pm 0.02 & $0.44 \mathrm{~A}$ & \pm 0.02 & $0.47 \mathrm{~A}$ & \pm 0.02 & $0.96 \mathrm{~B}$ & \pm 0.07 & $* * *$ & $*$ \\
\hline & DHA & 6.11 & \pm 0.29 & 6.69 & \pm 0.52 & 5.86 & \pm 0.21 & 6.53 & \pm 0.53 & & \\
\hline & $\sum n-3$ & $7.10 \mathrm{a}$ & \pm 0.28 & $7.78 \mathrm{ab}$ & \pm 0.54 & $7.29 \mathrm{a}$ & \pm 0.22 & $8.85 \mathrm{~b}$ & \pm 0.55 & $*$ & \\
\hline \multirow[t]{5}{*}{ heart } & ALA & 0.25 & \pm 0.03 & 0.34 & \pm 0.07 & 0.35 & \pm 0.04 & 0.33 & \pm 0.06 & & \\
\hline & EPA & $0.10 \mathrm{~A}$ & \pm 0.02 & $0.13 \mathrm{AB}$ & \pm 0.01 & $0.19 \mathrm{C}$ & \pm 0.01 & $0.16 \mathrm{BC}$ & \pm 0.02 & & $* * *$ \\
\hline & n-3 DPA & $1.38 \mathrm{a}$ & \pm 0.15 & $2.36 \mathrm{c}$ & \pm 0.08 & $1.83 \mathrm{~b}$ & \pm 0.08 & $2.51 \mathrm{c}$ & \pm 0.26 & $* * *$ & $*$ \\
\hline & DHA & $11.9 \mathrm{a}$ & \pm 0.47 & $13.1 \mathrm{~b}$ & \pm 0.24 & $12.4 \mathrm{ab}$ & \pm 0.40 & $13.2 \mathrm{~b}$ & \pm 0.29 & $*$ & \\
\hline & $\sum \mathrm{n}-3$ & $13.7 \mathrm{a}$ & \pm 0.50 & $15.9 \mathrm{bc}$ & \pm 0.26 & $14.8 \mathrm{ab}$ & \pm 0.47 & $16.2 \mathrm{c}$ & \pm 0.52 & $* * *$ & \\
\hline \multirow[t]{5}{*}{ lung } & ALA & 0.34 & \pm 0.03 & 0.26 & \pm 0.04 & 0.32 & \pm 0.03 & 0.32 & \pm 0.05 & & \\
\hline & EPA & $0.30 \mathrm{a}$ & \pm 0.04 & $0.34 \mathrm{ab}$ & \pm 0.04 & $0.42 \mathrm{~b}$ & \pm 0.03 & $0.37 \mathrm{ab}$ & \pm 0.03 & & $*$ \\
\hline & n-3 DPA & $0.61 \mathrm{a}$ & \pm 0.06 & $1.26 \mathrm{~b}$ & \pm 0.12 & $1.38 \mathrm{~b}$ & \pm 0.04 & $1.80 \mathrm{c}$ & \pm 0.11 & $* * *$ & $* * *$ \\
\hline & DHA & $1.51 \mathrm{~A}$ & \pm 0.19 & $2.02 \mathrm{~B}$ & \pm 0.18 & $2.16 \mathrm{~B}$ & \pm 0.07 & $2.19 \mathrm{~B}$ & \pm 0.09 & $*$ & $* *$ \\
\hline & $\sum n-3$ & $2.76 \mathrm{a}$ & \pm 0.29 & $3.88 \mathrm{~b}$ & \pm 0.34 & $4.27 \mathrm{bc}$ & \pm 0.09 & $4.68 \mathrm{c}$ & \pm 0.16 & $* *$ & $* * *$ \\
\hline \multirow[t]{5}{*}{ spleen } & ALA & 0.27 & \pm 0.05 & 0.64 & \pm 0.22 & 0.33 & \pm 0.02 & 0.49 & \pm 0.12 & $*$ & \\
\hline & EPA & $0.18 \mathrm{ab}$ & \pm 0.03 & $0.13 \mathrm{a}$ & \pm 0.02 & $0.19 \mathrm{ab}$ & \pm 0.02 & $0.22 \mathrm{~b}$ & \pm 0.03 & & \\
\hline & n-3 DPA & $0.72 \mathrm{a}$ & \pm 0.03 & $1.00 \mathrm{~b}$ & \pm 0.12 & $1.09 \mathrm{~b}$ & \pm 0.06 & $1.39 \mathrm{c}$ & \pm 0.08 & $* *$ & $* * *$ \\
\hline & DHA & 2.02 & \pm 0.10 & 1.95 & \pm 0.20 & 1.93 & \pm 0.11 & 1.98 & \pm 0.15 & & \\
\hline & $\sum \mathrm{n}-3$ & $3.18 \mathrm{a}$ & \pm 0.14 & $3.62 \mathrm{ab}$ & \pm 0.35 & $3.55 \mathrm{ab}$ & \pm 0.17 & $4.08 \mathrm{~b}$ & \pm 0.21 & $*$ & \\
\hline \multirow[t]{5}{*}{$\mathrm{RBC}$} & ALA & $0.59 \mathrm{~A}$ & \pm 0.11 & $0.68 \mathrm{AB}$ & \pm 0.23 & $1.06 \mathrm{~B}$ & \pm 0.09 & $0.42 \mathrm{~A}$ & \pm 0.07 & $* *$ & $*$ \\
\hline & EPA & $0.35 \mathrm{a}$ & \pm 0.06 & $0.48 \mathrm{ab}$ & \pm 0.11 & $0.47 \mathrm{ab}$ & \pm 0.04 & $0.63 \mathrm{~b}$ & \pm 0.10 & & \\
\hline & n-3 DPA & $0.80 \mathrm{a}$ & \pm 0.05 & $1.20 \mathrm{c}$ & \pm 0.03 & $1.05 \mathrm{~b}$ & \pm 0.05 & $1.46 \mathrm{~d}$ & \pm 0.07 & $* * *$ & $* * *$ \\
\hline & DHA & $3.66 \mathrm{ab}$ & \pm 0.20 & $4.23 \mathrm{a}$ & \pm 0.17 & $3.38 \mathrm{~b}$ & \pm 0.14 & $4.18 \mathrm{a}$ & \pm 0.37 & $* *$ & \\
\hline & $\sum n-3$ & $5.39 \mathrm{a}$ & \pm 0.26 & $6.58 \mathrm{~b}$ & \pm 0.29 & $5.96 \mathrm{a}$ & \pm 0.23 & $6.70 \mathrm{~b}$ & \pm 0.43 & $* *$ & \\
\hline
\end{tabular}

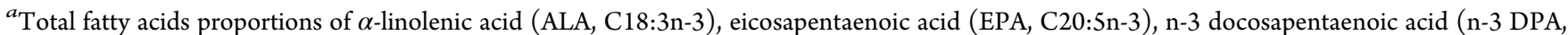
C22:5n-3), docosahexaenoic acid (DHA, C22:6n-3), and total n-3 long-chain polyunsaturated fatty acids ( $\sum$ n-3) in tissues of rats fed the vegetable oils blend diet (VO) or the vegetable oil and dairy lipid blend diet (DL) not supplemented or supplemented with 0.5\% DPA (VO+DPA and DL + DPA). Values are mean \pm SEM. DPA supplementation effect (DPA) compared both not supplemented groups with both supplemented groups; lipid mixture effect (LM) compared both VO groups with both DL groups $\left({ }^{*} p<0.05, * * p<0.01, * * * p 0.001\right)$. Different letters indicate significant differences for multiple comparisons (Tukey, $p<0.05$ ). Uppercase letters indicate a significant interaction between DPA and LM effects. nd, nondetected; FA, fatty acids; RBC, red blood cells.

affected by DPA supplementation in liver, plasma, brain, retina, and muscle.

Following the n-3 DPA supplementation, the DHA content in studied tissues ranked from $0.2 \%$ in skin to $15.5 \%$ in brain and was not detected in adipose tissues. More precisely, the proportion of DHA increased significantly in the spleen (1.2fold) and the lung (1.2-fold). The DHA content tended to increase in the bone marrow (1.6-fold, $p=0.099$ ) and the stomach $(1.5$-fold, $p=0.069)$. DHA levels were similar in both groups in the other tissues.

Following the n-3 DPA supplementation, the EPA content in studied tissues ranked from $0.1 \%$ in the bone marrow to $1.4 \%$ in the pancreas. More precisely, the proportion of EPA increased significantly in the liver (2.0-fold), the plasma (2.0fold), the spleen (1.5-fold), the lung (1.3-fold), and the stomach (2.6-fold). The EPA content tended to increase in the bone marrow (1.1-fold, $p=0.074)$ and the pancreas (1.4-fold, $p=0.096)$. The estimated retroconversion of DPA into EPA in the liver was $46.6 \% \pm 7.9 \%$. EPA was not detected in the brain, the retina, the skin, and adipose tissues.

Concerning n-6 PUFA, the ratio of the n- 6 PUFA (sum of C18:3 n-6, C20:3 n-6, C20:4 n-6, C22:4 n-6, and C22:5 n-6) divided by the n-6 PUFA precursor (C18:2 n-6) was used to estimate the n-6 PUFA conversion pathway rate (Figure 3 ).
Following the n-3 DPA supplementation, the ratio decreased significantly in the RBC (1.3-fold), the pancreas (1.3-fold), the liver (1.2-fold), the kidney (1.2-fold), and the brain (1.1-fold).

3.1.2. Global and Comparative Impact of $n-3$ DPA Supplementation on Tissues. To further underline the differences in tissue FA composition induced by n-3 DPA supplementation, an OPLS-DA was performed (Figure 4). All identified FA were taken into account in the model, which expressed $40.7 \%$ of the total variance $\mathrm{R}^{2} \mathrm{X}$ (CV-ANOVA, $p=$ 0.047 ) (see Supporting Information B for complete tissue FA profiles). A significant discrimination between both groups is obtained along with the horizontal axis (CV-ANOVA, $p<$ 0.05) (Figure 4A), showing that the n-3 DPA dietary supplementation affected the overall FA tissue compositions. $R^{2}$ (explaining class variance) and $Q^{2}$ (explaining class prediction) values were 0.986 and 0.776 , respectively. The n3 DPA supplemented group was discriminated to the right of the horizontal axis of the score plot (Figure 4A). Thus, the n-3 DPA group was positively associated with variables at the right of the loading plot (Figure 4B) and negatively associated with variables at the left of the loading plot. The converse occurs for the rats fed the control group. Moreover, the association is stronger for variables close to the origin of the vertical axis than distant variables. 
First, we hierarchized the different FA contents affected by n-3 DPA supplementation (Figure 4B). As a general result, n-3 DPA supplementation significantly increased only n-3 PUFA, decreased only n-6 PUFA, and did not impact saturated n-7 and n-9 FA. More precisely, among the n-3 PUFA, n-3 DPA > EPA > DHA > ALA were positively impacted by $n-3$ DPA supplementation. Among the n-6 PUFA, n-6 DPA > C22:4 n-6 $>$ C20:4 n-6 > C18:2 n-6 were negatively impacted by n-3 DPA supplementation.

We then were interested in the comparison between tissues (Figure 4B). When considering all FA contents, the tissues the most impacted by the n-3 DPA supplementation were ranked as follows: spleen $>$ lung $>$ heart $>$ liver $>$ skin $>$ gut $>$ kidney $>$ pancreas $>$ bone marrow $>$ epididymal adipose tissue $>\mathrm{RBC}>$ brain. When considering n-3 PUFA content, the tissues most impacted by the n-3 DPA supplementation were ranked as follows: spleen $>$ lung $>$ heart $>$ liver $>$ bone marrow $>$ epididymal fat $>$ skin $>$ kidney $>\mathrm{RBC} \gg$ brain. When considering n-6 PUFA content, the tissues most impacted by the n-3 DPA supplementation were ranked as follows: heart $>$ lung $>$ spleen $>$ liver $>$ pancreas $>$ skin $>$ kidney $>$ gut $>$ brain.

3.2. Experiment 2: Combined Effects of Dairy Lipid Mixture (DL) and n-3 DPA Supplementation after 6 weeks of Diet As Compared to a Vegetable Oils Mixture (VO). The major aim of experiment 2 was to study the potential impact of two lipid mixtures (lipid mixture effect: VO and $\mathrm{VO}+\mathrm{DPA}$ vs DL and DL+DPA) not supplemented or supplemented with DPA (DPA effect: VO and DL vs VO + DPA and DL+DPA) on PUFA metabolism. Moreover, we studied if the impact of n-3 DPA supplementation was affected by the lipid mixture (interaction between DPA effect and lipid mixture effect).

We focused on the FA composition of the liver as the major metabolic organ, and the heart, the spleen, and the lung as the most impacted tissues by the n- 3 DPA supplementation in experiment 1 . We also studied the FA composition of the RBC and the brain, particularly interesting for the potential impact of dairy lipids on these tissues, as previously described. ${ }^{25}$ The tables of tissues FA composition of all identified FA are presented in Supporting Information C, Tables S1-S6. At the end of experiment 2 , body weight gain, organ weight, and food intake did not differ significantly between groups (see Supporting Information A, Figure S2 and Table S1).

3.2.1. Dairy Lipids Improved n-3 PUFA Status in Tissues. We first considered the effect of the lipid mixture on n-3 PUFA metabolism (Table 2). The n-3 DPA content was higher in liver, heart, lung, spleen, and $\mathrm{RBC}$ of rats fed DL diets than in rats fed VO diets. The DHA content of rats fed DL diets was higher in the lung only, as well as the total n-3 PUFA content. The EPA content of rats fed DL diets was higher in the liver, the heart, and the lung. The ALA content of rats fed DL diets increased in the liver and the RBC as compared to VO diets. In brain phospholipids, the DHA content increased in the DL group as compared to both $\mathrm{VO}$ and $\mathrm{VO}+\mathrm{DPA}$ groups (Figure $5)$. The n-3 DPA supplementation did not increase the n-3 PUFA status in the brain (see Supporting Information C, Table S6 for brain complete FA profile).

We then considered the effect of the lipid mixture on $n-6$ PUFA metabolism (Table 3). The total n-6 PUFA increased in the heart, the lung, and the RBC. The n- 6 DPA content of rats fed DL diets decreased in the heart and the spleen. The adrenic acid (C22:4 n-6) content of rats fed DL diets decreased in the liver, while it increased in the lung. The arachidonic acid

\section{Brain DHA status}

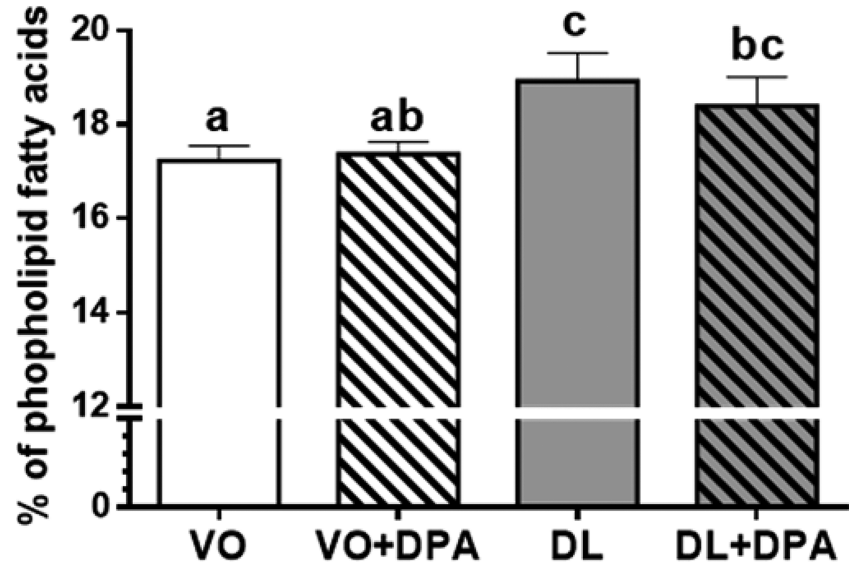

Figure 5. DHA proportion in brain phospholipids of rats fed the vegetable oils blend diet (VO) or the vegetable oil and dairy lipid blend diet (DL) not supplemented or supplemented with $0.5 \%$ DPA $(\mathrm{VO}+\mathrm{DPA}$ and DL+DPA). Values are mean \pm SEM. Different superscript characters indicate significant differences for Tukey posthoc test for multiple comparisons $(p<0.05)$.

(C20:4 n-6) content of rats fed DL diets decreased in the $\mathrm{RBC}$, while it increased in the lung. The LA content of rats fed $\mathrm{DL}$ diets increased in the liver, the heart, the spleen, and the RBC.

3.2.2. n-3 DPA Supplementation Increased n-3 PUFA and Decreased n-6 PUFA. We first considered the effect of the n-3 DPA supplementation on n-3 PUFA metabolism (Table 2). The n-3 DPA content as well as the total n-3 PUFA increased in all studied tissues after the n-3 DPA supplementation. The DHA content increased in the heart, the lung, and the RBC. The EPA content increased in the liver only. The estimated retroconversion of DPA into EPA in the liver was $35.1 \pm 6.4 \%$ and did not differ between the four groups. The ALA content increased in the spleen and the RBC.

We then considered the effect of the n-3 DPA supplementation on n-6 PUFA metabolism (Table 3). The total n-6 PUFA content decreased only in the heart after the n3 DPA supplementation. The n-6 DPA content decreased in the liver, the heart, and the spleen. The adrenic acid (C22:4n6) content decreased in the heart and the spleen. The arachidonic acid content decreased only in the spleen. The LA content decreased in the liver and the heart of n-3 DPA supplemented rats.

3.2.3. n-3 DPA Supplementation Differently Affected Tissue FA Composition in Combination with Dairy Lipids or Vegetable Oils Mixtures. We used redundancy analysis (RDA) to observe if the n-3 DPA supplementation affected the tissues FA composition differently, depending on the lipid mixture where n-3 DPA was included (VO or DL). We chose to study the four tissues most impacted by the n-3 DPA supplementation reported in experiment 1: the liver, the heart, the lung, and the spleen.

We first included all identified FA in the model to observe the potential interaction between n-3 DPA supplementation and the lipid mixture on the global fatty acid metabolism (Figure 6A). The model expressed $37.9 \%$ of constrained variance. The first component (horizontal axis) corresponded to the lipid mixture effect ( $\mathrm{VO}$ and $\mathrm{VO}+\mathrm{DPA}$ vs $\mathrm{DL}$ and $\mathrm{DL}$ $+\mathrm{DPA}, p=0.001$ ). The second component (vertical axis) 
Table 3. n-6 PUFA Tissue Contents ${ }^{a}$

\begin{tabular}{|c|c|c|c|c|c|c|c|c|c|c|c|}
\hline \multirow[b]{2}{*}{ liver } & \multirow{2}{*}{$\begin{array}{l}\text { FA \% } \\
\text { LA }\end{array}$} & \multicolumn{2}{|c|}{$\mathrm{VO}$} & \multicolumn{2}{|c|}{$\mathrm{VO}+\mathrm{DPA}$} & \multicolumn{2}{|c|}{$\mathrm{DL}$} & \multicolumn{2}{|c|}{$\mathrm{DL}+\mathrm{DPA}$} & \multirow{2}{*}{$\begin{array}{l}\text { DPA } \\
*\end{array}$} & \multirow{2}{*}{$\begin{array}{l}\mathrm{LM} \\
* * *\end{array}$} \\
\hline & & $7.58 \mathrm{a}$ & \pm 0.35 & $6.83 \mathrm{~b}$ & \pm 0.27 & $9.38 \mathrm{c}$ & \pm 0.27 & $10.25 \mathrm{~d}$ & \pm 0.26 & & \\
\hline & ARA & 15.0 & \pm 0.63 & 14.3 & \pm 0.92 & 14.1 & \pm 0.54 & 12.8 & \pm 1.00 & & \\
\hline & AdA & $0.26 \mathrm{a}$ & \pm 0.02 & $0.21 \mathrm{ab}$ & \pm 0.02 & $0.19 \mathrm{~b}$ & \pm 0.01 & $0.18 \mathrm{~b}$ & \pm 0.02 & $*$ & \\
\hline & n-6 DPA & $0.22 \mathrm{a}$ & \pm 0.02 & $0.19 a$ & \pm 0.02 & $0.19 \mathrm{a}$ & \pm 0.01 & $0.11 \mathrm{~b}$ & \pm 0.01 & $* *$ & \\
\hline & $\sum n-6$ & 23.8 & \pm 0.58 & 22.2 & \pm 1.10 & 24.8 & \pm 0.73 & 24.3 & \pm 1.13 & & \\
\hline \multirow[t]{5}{*}{ heart } & LA & $13.0 \mathrm{AB}$ & \pm 0.31 & $12.6 \mathrm{~A}$ & \pm 0.36 & $15.0 \mathrm{C}$ & \pm 0.34 & $13.8 \mathrm{~B}$ & \pm 0.18 & $* *$ & $* * *$ \\
\hline & ARA & 21.6 & \pm 0.34 & 21.0 & \pm 0.27 & 20.9 & \pm 0.33 & 20.7 & \pm 0.39 & & \\
\hline & AdA & $0.89 a$ & \pm 0.04 & $0.72 \mathrm{~b}$ & \pm 0.07 & $0.91 \mathrm{a}$ & \pm 0.03 & $0.72 \mathrm{~b}$ & \pm 0.05 & $* *$ & \\
\hline & n-6 DPA & $1.03 \mathrm{a}$ & \pm 0.07 & $0.84 \mathrm{~b}$ & \pm 0.05 & $0.86 \mathrm{ab}$ & \pm 0.06 & $0.69 \mathrm{~b}$ & \pm 0.04 & $* *$ & $* *$ \\
\hline & $\sum n-6$ & $37.2 \mathrm{a}$ & \pm 0.47 & $35.9 \mathrm{~b}$ & \pm 0.42 & $38.6 \mathrm{c}$ & \pm 0.43 & $36.7 \mathrm{ab}$ & \pm 0.42 & $* * *$ & $*$ \\
\hline \multirow[t]{5}{*}{ lung } & LA & $5.21 \mathrm{~A}$ & \pm 0.17 & $4.33 \mathrm{~B}$ & \pm 0.27 & $4.95 \mathrm{AB}$ & \pm 0.21 & $5.20 \mathrm{~A}$ & \pm 0.33 & & \\
\hline & ARA & $10.8 \mathrm{~A}$ & \pm 0.60 & $12.4 \mathrm{AB}$ & \pm 0.69 & $14.3 \mathrm{~B}$ & \pm 0.30 & $13.2 \mathrm{~B}$ & \pm 0.55 & $* * *$ & \\
\hline & AdA & $2.30 \mathrm{a}$ & \pm 0.25 & $2.48 \mathrm{a}$ & \pm 0.23 & $3.11 \mathrm{~b}$ & \pm 0.11 & $2.74 \mathrm{ab}$ & \pm 0.14 & $* *$ & \\
\hline & n-6 DPA & 0.23 & \pm 0.03 & 0.27 & \pm 0.04 & 0.27 & \pm 0.02 & 0.24 & \pm 0.02 & & \\
\hline & $\sum n-6$ & $18.9 \mathrm{~A}$ & \pm 0.79 & $20.0 \mathrm{~A}$ & \pm 0.77 & $23.3 \mathrm{~B}$ & \pm 0.39 & $22.0 \mathrm{~B}$ & \pm 0.45 & $* * *$ & \\
\hline \multirow[t]{5}{*}{ spleen } & LA & $4.19 \mathrm{a}$ & \pm 0.91 & $5.87 \mathrm{~b}$ & \pm 0.35 & $6.35 \mathrm{~b}$ & \pm 0.13 & $6.52 \mathrm{~b}$ & \pm 0.24 & $* *$ & \\
\hline & ARA & $20.7 \mathrm{a}$ & \pm 0.74 & $16.9 \mathrm{~b}$ & \pm 1.61 & $19.6 \mathrm{ab}$ & \pm 0.65 & $18.7 \mathrm{ab}$ & \pm 1.16 & $*$ & \\
\hline & AdA & $2.29 \mathrm{a}$ & \pm 0.11 & $1.68 \mathrm{c}$ & \pm 0.17 & $2.11 \mathrm{ab}$ & \pm 0.08 & $1.86 \mathrm{bc}$ & \pm 0.13 & $* *$ & \\
\hline & n-6 DPA & $0.29 a$ & \pm 0.02 & $0.23 \mathrm{~b}$ & \pm 0.03 & $0.24 \mathrm{ab}$ & \pm 0.01 & $0.20 \mathrm{~b}$ & \pm 0.02 & $*$ & $*$ \\
\hline & $\sum n-6$ & $28.5 \mathrm{ab}$ & \pm 0.70 & $25.5 \mathrm{a}$ & \pm 1.54 & $29.5 \mathrm{~b}$ & \pm 0.69 & $28.5 \mathrm{ab}$ & \pm 1.14 & $*$ & \\
\hline \multirow[t]{5}{*}{$\mathrm{RBC}$} & LA & $6.30 \mathrm{a}$ & \pm 0.17 & $6.38 \mathrm{a}$ & \pm 0.13 & $8.83 \mathrm{~b}$ & \pm 0.71 & $8.15 b$ & \pm 0.85 & $* * *$ & \\
\hline & ARA & $26.8 \mathrm{~A}$ & \pm 0.69 & $26.3 \mathrm{~B}$ & \pm 0.96 & $21.2 \mathrm{~A}$ & \pm 1.07 & $25.8 \mathrm{~A}$ & \pm 0.78 & $* *$ & $* * *$ \\
\hline & AdA & 1.02 & \pm 0.10 & 0.92 & \pm 0.09 & 0.81 & \pm 0.08 & 0.92 & \pm 0.08 & & \\
\hline & n-6 DPA & 0.46 & \pm 0.02 & 0.45 & \pm 0.02 & 0.40 & \pm 0.05 & 0.38 & \pm 0.02 & & \\
\hline & $\sum n-6$ & $35.3 \mathrm{~A}$ & \pm 0.76 & $34.9 \mathrm{~A}$ & \pm 0.97 & $32.0 \mathrm{~B}$ & \pm 0.86 & $36.2 \mathrm{~A}$ & \pm 0.34 & $* * *$ & $* *$ \\
\hline
\end{tabular}

${ }^{a}$ Proportions of linoleic acid (LA, C18:2n-6), arachidonic acid (ARA, C20:4n-6), adrenic acid (AdA, C22:4n-6), n-6 docosapentaenoic acid (n-6 DPA, C22:5n-6), and total n-6 long-chain polyunsaturated fatty acids $\left(\sum n-6\right)$ in tissues of rats fed the vegetable oils blend diet (VO) or the vegetable oil and dairy lipid blend diet (DL) not supplemented or supplemented with $0.5 \%$ DPA (VO+DPA and DL+DPA). Values are mean \pm SEM. DPA supplementation effect (DPA) compared both not supplemented groups with both supplemented groups; lipid mixture effect (LM) compared both VO groups with both DL groups $\left(* p<0.05,{ }^{*} p<0.01, * * * p<0.001\right)$. Different letters indicate significant differences for multiple comparisons (Tukey, $p<0.05$ ). Uppercase letters indicate a significant interaction between DPA and LM effects. FA, fatty acids; RBC, red blood cells.

corresponded to the n-3 DPA supplementation (VO and DL vs $\mathrm{VO}+\mathrm{DPA}$ and DL+DPA, $p=0.007)$. Differences between FA profiles were more enhanced by the lipid mixture effect $(73.9 \%$ of constrained variance) than by the n-3 DPA supplementation (17.6\% of constrained variance). The significant interaction between the lipid mixture and the n-3 DPA supplementation $(p<0.020)$ demonstrated that the n-3 DPA supplementation differently affected rats depending of the lipid mixture. Therefore, if we then compared each group, the n-3 DPA supplementation did not affect the total FA profiles when rats were fed with DL diets (DL vs DL+DPA, $p=0.3710$ ). Conversely, the total FA profiles of rats fed VO diets were impacted by the n-3 DPA supplementation (VO vs VO+DPA, $p=0.0012)$. Moreover, both DL and DL+DPA groups were significantly different from both $\mathrm{VO}$ and $\mathrm{VO}+\mathrm{DPA}$ groups $(p=$ 0.0012). The C14:0, C15:0, and the n-3 DPA to a lesser extent were the most associated FA with both DL diets (see Supporting Information D, Figure S1 for loading plots).

As DL diets were mostly discriminated by saturated fatty acids (C14:0 and C15:0) and n-3 DPA, we then considered all of the identified PUFA to observe only the potential interaction of the n-3 DPA supplementation and the lipid mixture on the PUFA acid metabolism (Figure 6B). The model expressed $31.4 \%$ of constrained variance. The first component expressed $68.2 \%$ of constrained variance and significantly discriminated all groups $(p<0.05)$. The first component was positively characterized by the n-3 PUFA, and negatively by the $\mathrm{n}-6$ PUFA (Figure $6 \mathrm{~B}$ ). Thus, the VO group was associated with the highest n-6 PUFA status, while the DL +DPA group was associated with the highest n-3 PUFA status. The VO+DPA group had an intermediate PUFA status between the VO and the DL group. The DL group had an intermediate PUFA status between the VO+DPA and the DL + DPA group. In conclusion, the n-3 PUFA global status corresponded to $\mathrm{VO}<\mathrm{VO}+\mathrm{DPA}<\mathrm{DL}<\mathrm{DL}+\mathrm{DPA}$ (see Supporting Information D, Figure S2 for loading plots).

3.2.4. Plasma Cholesterol Decreased with n-3 DPA Supplementation and Increased with DL Diet. DL diets contained $6.6 \mathrm{mg}$ of cholesterol/100 $\mathrm{g}$ of diet, whereas cholesterol was absent in VO diets. Plasma total cholesterol increased in the DL group only (Figure 7). This increase in total cholesterol was associated with an increase in cholesterol esters and an increase of the non-HDL cholesterol fraction and so the cholesterol/HDL cholesterol ratio. The supplementation of DL diet with n-3 DPA maintained all of these amounts at the same level as both $\mathrm{VO}$ and $\mathrm{VO}+\mathrm{DPA}$ groups. 

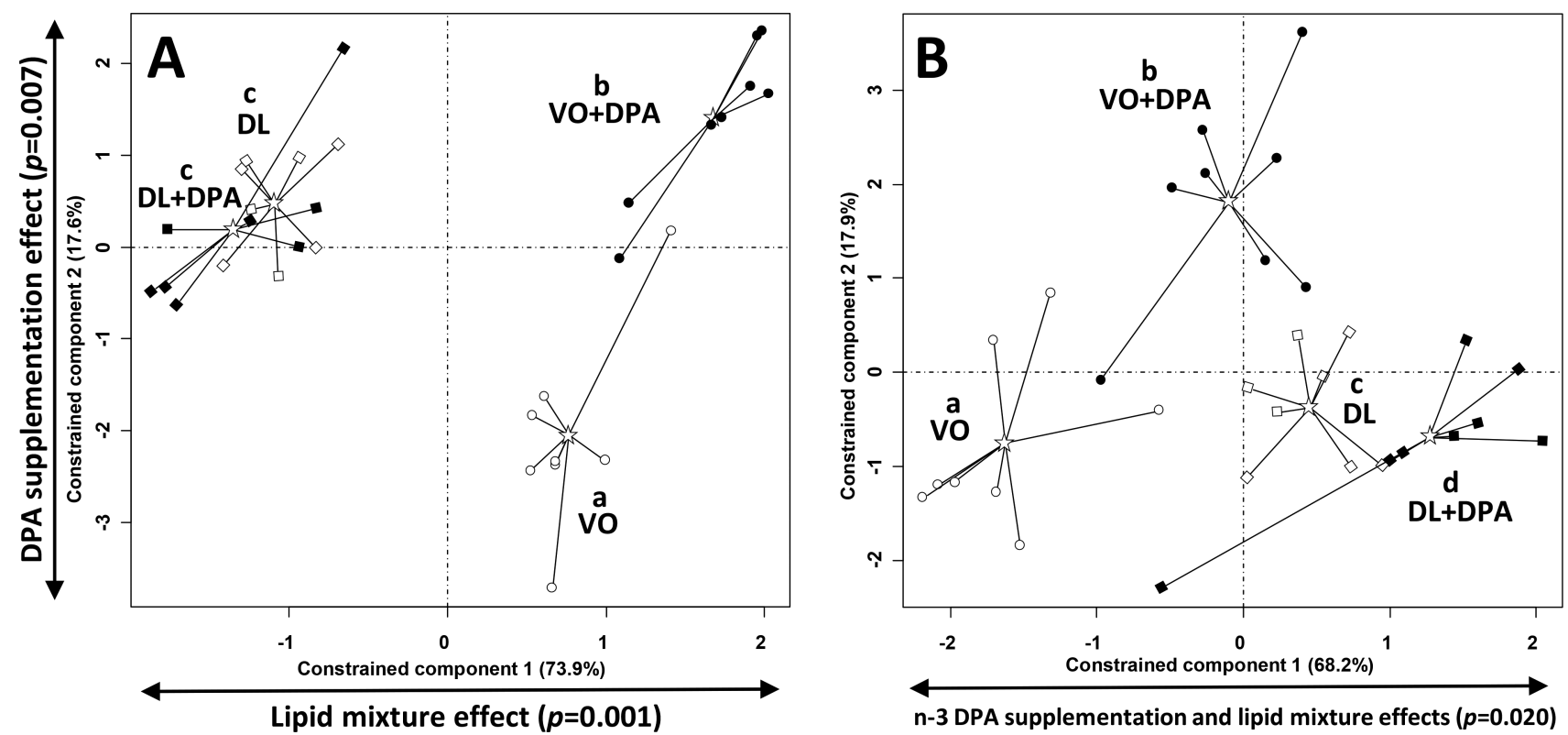

Figure 6. Redundancy analysis of fatty acids (FA) composition of the liver, heart, lung, and spleen for (A) all identified FA, and (B) long-chain polyunsaturated FA, of rats fed the vegetable oils blend diet $(\mathrm{VO}, \mathrm{O})$ or the vegetable oil and dairy lipid blend diet (DL, $\square)$ not supplemented or supplemented with $0.5 \% \mathrm{DPA}$ (VO+DPA, $\mathbf{0}$; and DL+DPA, $\mathbf{\square}$ ). The it represented barycenter of each group of rats. A permutation test was performed to consider the significance of the n-3 DPA supplementation effect (VO and DL vs VO+DPA and DL-DPA) and the lipid mixture effect (VO and VO+DPA vs DL and DL+DPA) with the two components, or considering their interaction (n-3 DPA supplementation:lipid mixture effects). This test was followed by pairwise comparisons using fitting factor into an ordination to assess the significance between the four groups ( $p$ $<0.05$ ), indicated by different superscript characters on the group name. Both loadings plot are presented in Supporting Information D, Figures 1 and 2 .

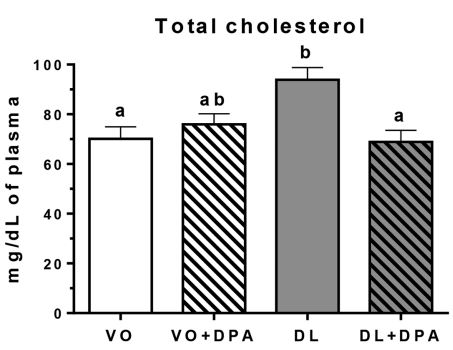

Total/ HDL cholesterol

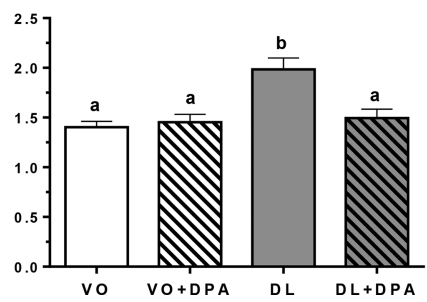

Cholesteryl esters

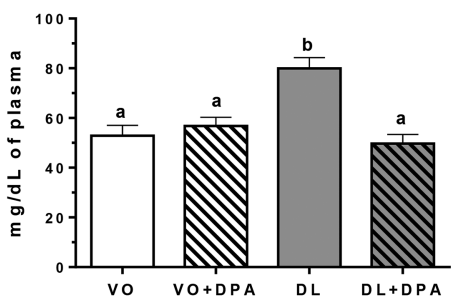

Non-HDL cholesterol

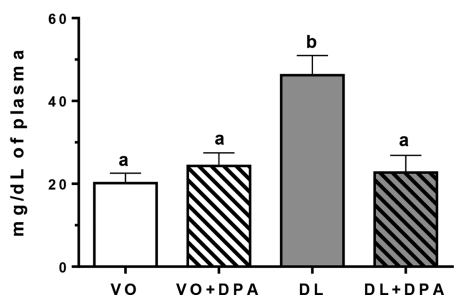

Free cholesterol

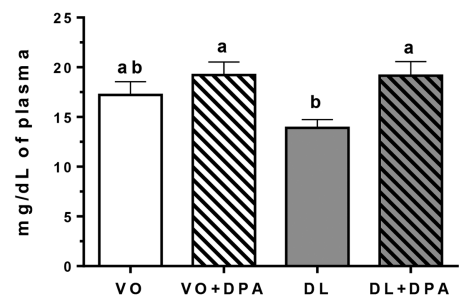

HDL cholesterol

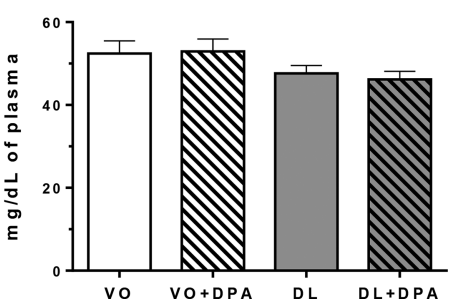

Figure 7. Plasma cholesterol concentrations of rats fed the vegetable oils blend diet (VO) or the vegetable oil and dairy lipid blend diet (DL) not supplemented or supplemented with $0.5 \%$ DPA (VO+DPA and DL+DPA). Values are mean \pm SEM. Different superscript characters indicate significant differences for Tukey posthoc test for multiple comparisons $(p<0.05)$, following the one-way ANOVA if significant $(p<0.05)$.

\section{DISCUSSION}

This study first addressed the impact of the nutritional n-3 DPA supplementation on tissues FA composition after 3 or 6 weeks of diet.

Nowadays, only few studies have examined the nutritional and biochemical effects of n-3 DPA in vivo. This could be mainly due to the high cost and the limited availability of highly purified DPA these days, ${ }^{17,34,35}$ not allowing wide intervention studies in humans for the moment. In this study, we proposed an innovative approach to purify n-3 DPA from fish oil enriched in n-3 PUFA by liquid chromatography (see section 2.2). This methodology, accessible in research laboratory, could help.

First, we showed that n-3 DPA supplementation increased n3 DPA content only in some tissues: the spleen, the lung, the heart, the liver, the RBC, the bone marrow, and the kidney. This specificity could come from the fact that the tissues most impacted by the n-3 DPA supplementation are (i) either tissues in which the metabolism of fatty acids is important and the enzymes of the PUFA conversion pathways are strongly 
expressed (liver, kidney, bone marrow), ${ }^{36}$ (ii) either tissues rich in mitochondria and energy intensive, the energetic role being the first quantitative use of fatty acids (heart, lung), ${ }^{37}$ (iii) either marker tissues of food consumption and fatty acid metabolism of animals (RBC, spleen), ${ }^{38}$ or (iv) either tissues exhibiting the highest proportions of n-3 DPA. ${ }^{39}$

Despite the relative lack of literature on the subject, our results are of interest when considering the physiological effects reported in these tissues. Concerning the spleen, a major organ involved in inflammation regulation, some experiments showed that n-3 DPA reduced inflammation in in vitro models, ${ }^{40}$ associated with the action of some hydroxymetabolites directly derived from n-3 DPA like resolvins. ${ }^{41}$ Concerning the lung, one epidemiological study showed that n-3 DPA is the most potent fatty acid associated with better forced expiratory volume and could prevent chronic obstructive pulmonary disease. ${ }^{42}$ Indeed, in addition to its anti-inflammatory properties, n-3 DPA have antiproteolytic and antioxidative abilities by decreasing nuclear factor-kappa $B$ $(\mathrm{NF}-\kappa \mathrm{B})$ and $\mathrm{p} 38$ mitogen-activated protein kinases (p38 MAPK) activation, leading to a decrease in vascular endothelial growth factor (VEGF), and matrix metalloproteinase-2 and -9 (MMP-2 and MMP-9) expression levels in lung in a model of rat pulmonary hypertension. ${ }^{43}$ Concerning the heart, n-3 DPA seems to exert similar cardiometabolic protection effects as DHA in high-fat diet fed mice, ${ }^{44}$ and a high n-3 DPA RBC level was associated with a lower risk of metabolic syndrome in human adults. ${ }^{3,5}$ These effects could arise from the capacity of dietary DPA to decrease plasma lipid parameters ${ }^{45}$ by inhibiting the expression of genes involved in the lipogenesis like Sterol Regulating Element Binding Protein (SREBP), 3Hydroxy-3-Methyl-Glutaryl-Coenzyme A reductase (HMGCoA-R), Acetyl Coenzyme A Carboxylase (ACC), and Fatty Acid Synthase (FAS). ${ }^{46}$ Moreover, some studies showed that n-3 DPA inhibited platelet aggregation stimulated by collagen or arachidonic acid by accelerating the lipoxygenase pathway and by interfering with the cyclooxygenase pathway dosedependently. ${ }^{47}$ These suggested effects linked to n-3 DPA could arise from the recently described bioactive metabolites derived from n-3 DPA, which could require a special attention in further studies. ${ }^{16,48}$ Surprisingly, while n-3 DPA has been described to exert a neuroprotective effect, we did not found a major change in brain FA composition following the n-3 DPA supplementation, but brain n-3 DPA content increased following the n-3 DPA dietary supplementation. ${ }^{4}$ We now wonder if the effects of n-3 DPA are independent of the other n-3 PUFA or shared with them. ${ }^{14}$

On the other hand, the n-3 DPA could be interesting to lead to an increase in the total n-3 PUFA status. It is well-known that the n-3 PUFA conversion pathway was described as limited by the $\Delta-6$ desaturase enzyme, the elongase- 2 enzyme, and the final step of $\beta$-peroxisomal oxidation of the C24:6n-3 to DHA. ${ }^{49}$ The elongase- 2 acts twice in PUFA conversion pathway, one time in association with the elongase-5 to convert EPA to DPA (or arachidonic acid to C22:4n-6) and another time to convert DPA to C24:5 n-3 (or C22:4n-6 to C24:4n-6), for the n-3 (and n-6) conversion pathway, respectively. ${ }^{50} \mathrm{~A}$ few years ago, some authors showed that the elongase- 2 enzyme could be the more limiting step to the conversion of n-3 DPA to DHA in brain astrocyte ${ }^{51}$ and in rat liver. ${ }^{7}$ As the direct supplementation with n-3 DPA shunted the contribution of the elongase- 2 for converting EPA to $n-3$ DPA, one could hypothesize that n-3 DPA could be a good precursor for DHA or act as an in vivo stock of DHA. ${ }^{24,25}$ We showed a significant but slight increase in DHA content in the spleen and in the lung after 3 weeks of n-3 DPA supplementation and of the lung, the heart, and the RBC after 6 weeks. The n-3 DPA could therefore be considered for its ability to increase the DHA status. However, we must keep in mind that the increase in DHA remained slight. These results are in good agreement with previous reports describing a low level of the saturation plateau in the conversion pathway to DHA. ${ }^{6,7,9,10}$

We also showed in both experiments that a large part of the n-3 DPA content in the liver was retroconverted into EPA ( $46 \%$ and $35 \%$ of apparent retroconversion). Indeed, the EPA content increased in the liver, the plasma, the spleen, and the lung in our study. The n-3 DPA apparent retroconversion, as well as the DHA apparent retroconversion to EPA, were previously described in vitro ${ }^{52}$ and in vivo, ${ }^{53}$ indicating that both n-3 DPA and DHA retroconversion involved the peroxisomal acyl-CoA oxidase. $^{54}$

Another point of our study is the decrease in $n-6$ PUFA content in tissues following the n-3 DPA supplementation, and mainly n-6 DPA and adrenic acid (C22:4 n-6). We also showed by OPLS-DA that n-3 DPA supplementation only impacted n-3 and n-6 PUFA tissue compositions, and not saturated n-7 and n-9 FA. These results are surely due to the similarity of both n-3 and n-6 conversion pathways as compared to each others and by the competition effect of $n$ 3 and n-6 PUFA on the $\Delta-6, \Delta-5$ desaturases and elongase-2 enzymes, which act in the synthesis of n-6 DPA from linoleic acid. $^{55}$

Furthermore, our results are interesting in terms of human nutrition because n-3 DPA is the only n-3 PUFA between EPA and DHA that is present in diet source in non-negligible amounts. ${ }^{17}$ Thus, we showed for the first time that DPA intake should be considered as a novel source of EPA as well as DHA for assessing the n-3 LC-PUFA nutritional status in rats, and to a larger extent in humans because the DPA content of products from animal husbandry or agriculture is not taken into account nowadays. ${ }^{17}$ Moreover, n-3 DPA decreased n-6 PUFA status and could have interesting and poorly known beneficial physiological effects that need more investigations.

This study second addressed the impact of the lipid mixture to modulate the effects of the n-3 DPA supplementation on the FA composition of the tissues most impacted by the n-3 DPA supplementation. Indeed, the second main finding of our study was that a partial incorporation of dairy lipids in the diet increased the PUFA content in tissues, as compared to a diet composed of a vegetable oil blend. Interestingly, this increase in PUFA status was higher in the nonsupplemented DL group than in the VO+DPA group, suggesting a more important impact of the lipid mixture than the direct n-3 DPA supplementation. Moreover, the n-3 PUFA status increasing effect was higher in the DL+DPA group than in the DL group in all tissues except in the brain, which was only affected by the lipid mixture. This showed an additive effect of dairy lipids and n-3 DPA supplementation on PUFA status. It has been previously shown that dairy lipids could improve the n-3 PUFA tissue content, principally up to n-3 DPA in most organs and up to DHA in the brain and retina in specific conditions. ${ }^{21,23-25,56}$

Three mechanistic hypotheses could explain the increase of n-3 PUFA with DL diets. First, it has been reported that myristic acid (C14:0) present in dairy lipids improved the 
activity and the mRNA expression of the elongase- 2 and the $\Delta$ 6 desaturase, the limiting enzymes of the n-3 and n- 6 PUFA conversion pathway, ${ }^{57}$ resulting in an increase in PUFA tissues content. ${ }^{58}$ Second, dairy lipids contain short- and mediumchain FA, which have a higher $\beta$-mitochondrial oxidation rate than ALA, ${ }^{59}$ and could so prevent part of the $\beta$-oxidation of PUFA precursors. ${ }^{60}$ In our study, ALA content was higher in the liver of the DL group, strengthening this hypothesis. Third, DL diets contained a lower level of oleic acid as compared to VO diet. As oleic acid is also a substrate of $\Delta-6$ desaturase, it could also compete with this enzyme more for $\mathrm{VO}$ groups than for DL groups. ${ }^{61}$ These results open new perspectives for the improvement of n-3 LC-PUFA status in early life in humans, through the incorporation of dairy lipids instead of high amounts of DHA. Indeed, the lipid compositions of our diets were based on commercial infant formulas, and most infant formula contains a mixture of vegetable oils and no dairy lipids, although closer to the composition of breastmilk. ${ }^{62}$

To conclude, the $0.5 \%$ n-3 DPA supplementation increased some EPA and DHA tissue content and mainly affected the spleen, the heart, the lung, and the liver. A partial incorporation of dairy lipids in the diet increased n-3 PUFA status. Moreover, the n-3 DPA supplementation combined with a partial incorporation of dairy lipids had a positive and complementary effect on the n-3 PUFA status in all studied tissues except in the brain. Finally, the DHA status increased in brain phospholipids with dairy lipid mixture only.

\section{ASSOCIATED CONTENT}

\section{S Supporting Information}

The Supporting Information is available free of charge on the ACS Publications website at DOI: 10.1021/acs.jafc.8b03069.

Supporting Information A, diets and animals; Figure S1, purification of n-3 DPA by liquid chromatography; Figure S2, rats cumulated body weight gain (A) and total weight gain (B); Table S1, organs weight at the end of the experimentation; Supporting Information B, fatty acid composition of tissues of experiment 1; Table S1, liver, red blood cells, and plasma total lipid fatty acid composition; Table S2, gut, stomach, and heart fatty acid composition of total lipids; Table S3, kidney, brain, and retina fatty acid composition of total lipids; Table S4, spleen, lung, and bone marrow fatty acid composition of total lipids; Table S5, pancreas, epididymal adipose tissue (TAE), and skin fatty acid composition of total lipids; Table S6, subcutaneous adipose tissue (SCAT), muscle, and testis fatty acid composition of total lipids; Supporting Information C, fatty acid composition of tissues of experiment 2; Table S1, liver fatty acids composition of total lipids; Table S2, heart fatty acids composition of total lipids; Table S3, lung fatty acids composition of total lipids; Table S4, spleen fatty acids composition of total lipids; Table S5, red blood cells fatty acids composition of total lipids; Table S6, brain fatty acids composition of phospholipids; Supporting Information D, loadings plot of Figure 3; Figure S1, loadings plot of Figure 3A; Figure S2, loadings plot of Figure 3B (PDF)

\section{AUTHOR INFORMATION}

\section{Corresponding Author}

*Tel.: +33-223-485-547. Fax: +33-223-485-550. E-mail: philippe.legrand@agrocampus-ouest.fr.

ORCID $\odot$

Gaetan Drouin: 0000-0001-8855-1525

Etienne Guillocheau: 0000-0002-1617-9936

Philippe Legrand: 0000-0001-5763-4854

\section{Author Contributions}

G.D., P.L., C.B., P.L.R., D.C., and V.R. contributed to the conception and design of the project. G.D. conducted the literature search, the experimentations, the acquisition and analysis of data, and wrote the first version of the manuscript. G.D. and E.G. performed statistical analysis. G.D., P.L., D.C., C.B., V.R., and E.G. contributed to the revision of the manuscript. All authors read and approved the final work.

\section{Funding}

This research was funded by Lactalis Group, grant no. R2014247.

\section{Notes}

The authors declare the following competing financial interest(s): This research was funded by [Lactalis Group], Grant number: [R2014-247]. Baudry C. and Le Ruyet P. are employed by Lactalis group.

\section{ACKNOWLEDGMENTS}

We would like to thank Morgan Lucas for his technical assistance. We are indebted to Xavier Blanc (UPAE, INRA Jouy-en-Josas, France) for the preparation of the lipid-free base necessary for the realization of the diets. We are grateful to Josephine Aronica for proofreading the English editing and academic writing of the paper.

\section{ABBREVIATIONS USED}

ALA, $\alpha$-linolenic acid; DL, blend of vegetable oils and dairy lipids; DHA, docosahexaenoic acid; EE, ethyl ester(s); EPA, eicosapentaenoic acid; FA, fatty acid(s); fdr, false discovery rate method; GC-MS, gas chromatography-mass spectrometry; HDL-cholesterol, high-density lipoprotein cholesterol; LA, linoleic acid; n-3 DPA, n-3 docosapentaenoic acid; OPLSDA, orthogonal partial least-squares discriminant analysis; PUFA, long-chain polyunsaturated fatty acid(s); RBC, red blood cells; RDA, redundancy analysis; SMCFA, short- and medium-chain fatty acid(s); TLC, thin-layer chromatography; VO, blend of vegetable oils

\section{REFERENCES}

(1) Simopoulos, A. P.; Leaf, A.; Salem, N. Workshop Statement on the Essentiality of and Recommended Dietary Intakes for Omega-6 and Omega-3 Fatty Acids. Prostaglandins, Leukotrienes Essent. Fatty Acids 2000, 63 (3), 119-121.

(2) Brenna, J. T.; Carlson, S. E. Docosahexaenoic Acid and Human Brain Development: Evidence That a Dietary Supply Is Needed for Optimal Development. J. Hum. Evol. 2014, 77, 99-106.

(3) Dai, X.; Chen, Y.; Zeng, F.; Sun, L.; Chen, C.; Su, Y. Association between N-3 Polyunsaturated Fatty Acids in Erythrocytes and Metabolic Syndrome in Chinese Men and Women. Eur. J. Nutr. 2016, 55 (3), 981-989.

(4) Dyall, S. C. Long-Chain Omega-3 Fatty Acids and the Brain: A Review of the Independent and Shared Effects of EPA, DPA and DHA. Front. Aging Neurosci. 2015, 7, 1. 
(5) Skulas-Ray, A. C.; Flock, M. R.; Richter, C. K.; Harris, W. S.; West, S. G.; Kris-Etherton, P. M. Red Blood Cell Docosapentaenoic Acid (DPA n-3) Is Inversely Associated with Triglycerides and CReactive Protein (CRP) in Healthy Adults and Dose-Dependently Increases Following n-3 Fatty Acid Supplementation. Nutrients 2015, 7 (8), 6390-6404.

(6) Brenna, J. T.; Salem, N.; Sinclair, A. J.; Cunnane, S. C. $\alpha$ Linolenic Acid Supplementation and Conversion to n-3 Long-Chain Polyunsaturated Fatty Acids in Humans. Prostaglandins, Leukotrienes Essent. Fatty Acids 2009, 80 (2-3), 85-91.

(7) Gregory, M. K.; Gibson, R. A.; Cook-Johnson, R. J.; Cleland, L. G.; James, M. J. Elongase Reactions as Control Points in Long-Chain Polyunsaturated Fatty Acid Synthesis. PLoS One 2011, 6 (12), e29662.

(8) Aliche-Djoudi, F.; Podechard, N.; Chevanne, M.; Nourissat, P.; Catheline, D.; Legrand, P.; Dimanche-Boitrel, M. T.; LagadicGossmann, D.; Sergent, O. Physical and Chemical Modulation of Lipid Rafts by a Dietary N-3 Polyunsaturated Fatty Acid Increases Ethanol-Induced Oxidative Stress. Free Radical Biol. Med. 2011, 51 (11), 2018-2030.

(9) Lin, Y. H.; Salem, N. Whole Body Distribution of Deuterated Linoleic and $\alpha$-Linolenic Acids and Their Metabolites in the Rat. J. Lipid Res. 2007, 48 (12), 2709-2724.

(10) Burdge, G. C.; Calder, P. C. Conversion of $\alpha$-Linolenic Acid to Longer-Chain Polyunsaturated Fatty Acids in Human Adults. Reprod., Nutr., Dev. 2005, 45 (5), 17.

(11) Walker, C. G.; Jebb, S. A.; Calder, P. C. Stearidonic Acid as a Supplemental Source of $\omega$-3 Polyunsaturated Fatty Acids to Enhance Status for Improved Human Health. Nutrition 2013, 29 (2), 363369.

(12) Pawar, A.; Jump, D. B. Unsaturated Fatty Acid Regulation of Peroxisome Proliferator-Activated Receptor $\alpha$ Activity in Rat Primary Hepatoctes. J. Biol. Chem. 2003, 278 (38), 35931-35939.

(13) Miller, E.; Kaur, G.; Larsen, A.; Peng Loh, S.; Loh, S. P.; Linderborg, K.; Weisinger, H. S.; Turchini, G. M.; Cameron-Smith, D.; Sinclair, A. J. A Short-Term n-3 DPA Supplementation Study in Humans. Eur. J. Nutr. 2013, 52 (3), 895-904.

(14) Kaur, G.; Guo, X. F.; Sinclair, A. J. Short Update on Docosapentaenoic Acid: A Bioactive Long-Chain n-3 Fatty Acid. Curr. Opin. Clin. Nutr. Metab. Care January 2016, 19, 88-91.

(15) Markworth, J. F.; Kaur, G.; Miller, E. G.; Larsen, A. E.; Sinclair, A. J.; Maddipati, K. R.; Cameron-Smith, D. Divergent Shifts in Lipid Mediator Profile Following Supplementation with N-3 Docosapentaenoic Acid and Eicosapentaenoic Acid. FASEB J. 2016, 30 (11), 3714-3725.

(16) Dalli, J.; Colas, R. A.; Serhan, C. N. Novel N-3 Immunoresolvents: Structures and Actions. Sci. Rep. 2013, 3 (1), 1940.

(17) Byelashov, O. A.; Sinclair, A. J.; Kaur, G. Dietary Sources, Current Intakes, and Nutritional Role of Omega-3 Docosapentaenoic Acid. Lipid Technol. 2015, 27 (4), 79-82.

(18) Rahmawaty, S.; Charlton, K.; Lyons-Wall, P.; Meyer, B. J. Dietary Intake and Food Sources of EPA, DPA and DHA in Australian Children. Lipids 2013, 48 (9), 869-877.

(19) Jia, X.; Pakseresht, M.; Wattar, N.; Wildgrube, J.; Sontag, S.; Andrews, M.; Subhan, F. B.; McCargar, L.; Field, C. J. APrON study team. Women Who Take N-3 Long-Chain Polyunsaturated Fatty Acid Supplements during Pregnancy and Lactation Meet the Recommended Intake. Appl. Physiol., Nutr., Metab. 2015, 40 (5), 474-481.

(20) Schuchardt, J. P.; Hahn, A. Bioavailability of Long-Chain Omega-3 Fatty Acids. Prostaglandins, Leukotrienes Essent. Fatty Acids 2013, 89 (1), 1-8.

(21) Dinel, A. L.; Rey, C.; Bonhomme, C.; Le Ruyet, P.; Joffre, C.; Layé, S. Dairy Fat Blend Improves Brain DHA and Neuroplasticity and Regulates Corticosterone in Mice. Prostaglandins, Leukotrienes Essent. Fatty Acids 2016, 109, 29-38.

(22) Delplanque, B.; Du, Q.; Agnani, G.; Le Ruyet, P.; Martin, J. C. C. A Dairy Fat Matrix Providing Alpha-Linolenic Acid (ALA) Is
Better than a Vegetable Fat Mixture to Increase Brain DHA Accretion in Young Rats. Prostaglandins, Leukotrienes Essent. Fatty Acids 2013, 88 (1), 115-120.

(23) Ezanno, H.; Beauchamp, E.; Catheline, D.; Legrand, P.; Rioux, V. Beneficial Impact of a Mix of Dairy Fat with Rapeseed Oil on N-6 and n-3 PUFA Metabolism in the Rat: A Small Enrichment in Dietary Alpha-Linolenic Acid Greatly Increases Its Conversion to DHA in the Liver. Eur. J. Lipid Sci. Technol. 2015, 117 (3), 281-290.

(24) Drouin, G.; Catheline, D.; Sinquin, A.; Baudry, C.; Le Ruyet, P.; Rioux, V.; Legrand, P. Incorporation of Dairy Lipids in the Diet Increased Long-Chain Omega-3 Fatty Acids Status in Post-Weaning Rats. Front. Nutr. 2018, 1 DOI: 10.3389/fnut.2018.00042.

(25) Du, Q.; Martin, J. C.; Agnani, G.; Pages, N.; Leruyet, P.; Carayon, P.; Delplanque, B. Dairy Fat Blends High in $\alpha$-Linolenic Acid Are Superior to n-3 Fatty-Acid-Enriched Palm Oil Blends for Increasing DHA Levels in the Brains of Young Rats. J. Nutr. Biochem. 2012, 23 (12), 1573-1582.

(26) Enti, S. C. I.; Opi, F. I. C.; On, N. I. Scientific Opinion on the Tolerable Upper I Ntake Level of Eicosapentaenoic Acid (EPA), Docosahexaenoic Acid (DHA) and Docosapentaenoic Acid. EFSA J. 2012, 10, 2815 .

(27) McNamara, R. K.; Able, J.; Jandacek, R.; Rider, T.; Tso, P. Gender Differences in Rat Erythrocyte and Brain Docosahexaenoic Acid Composition: Role of Ovarian Hormones and Dietary Omega-3 Fatty Acid Composition. Psychoneuroendocrinology 2009, 34 (4), $532-539$.

(28) ANSES. Actualisation des Apports Nutritionnels Conseillés pour les acides gras, 2011.

(29) Wolff, R. L.; Bayard, C. C.; Fabien, R. J. Evaluation of Sequential Methods for the Determination of Butterfat Fatty Acid Composition with Emphasis Ontrans-18:1 Acids. Application to the Study of Seasonal Variations in French Butters. J. Am. Oil Chem. Soc. 1995, 72 (12), 1471-1483.

(30) Kalivodová, A.; Hron, K.; Filzmoser, P.; Najdekr, L.; Janečková, H.; Adam, T. PLS-DA for Compositional Data with Application to Metabolomics. J. Chemom. 2015, 29 (1), 21-28.

(31) van den Berg, R. A.; Hoefsloot, H. C. J.; Westerhuis, J. A.; Smilde, A. K.; van der Werf, M. J. Centering, Scaling, and Transformations: Improving the Biological Information Content of Metabolomics Data. BMC Genomics 2006, 7, 142.

(32) Wiklund, S.; Johansson, E.; Sjöström, L.; Mellerowicz, E. J.; Edlund, U.; Shockcor, J. P.; Gottfries, J.; Moritz, T.; Trygg, J. Visualization of \textsc\{gc/Tof-Ms\}-Based Metabolomics Data for Identification of Biochemically Interesting Compounds Using \textsc\{opls\} Class Models. Anal. Chem. 2007, 80 (1), 115-22.

(33) Hervé, M. R.; Nicolè, F.; Cao, K. L. Multivariate Analysis of Multiple Datasets: A Practical Guide for Chemical Ecology, 2018.

(34) Mu, H.; Jin, J.; Xie, D.; Zou, X.; Wang, X.; Wang, X.; Jin, Q. Combined Urea Complexation and Argentated Silica Gel Column Chromatography for Concentration and Separation of PUFAs from Tuna Oil: Based on Improved DPA Level. J. Am. Oil Chem. Soc. 2016, 93 (8), 1157-1167.

(35) Yamamura, R.; Shimomura, Y. Industrial High-Performance Liquid Chromatography Purification of Docosahexaenoic Acid Ethyl Ester and Docosapentaenoic Acid Ethyl Ester from Single-Cell Oil. J. Am. Oil Chem. Soc. 1997, 74 (11), 1435-1440.

(36) Cho, H. P.; Nakamura, M. T.; Clarke, S. D. Cloning, Expression, and Nutritional Regulation of the Mammalian $\Delta-6$ Desaturase. J. Biol. Chem. 1999, 274 (1), 471-477.

(37) Ghasemifard, S.; Hermon, K.; Turchini, G. M.; Sinclair, A. J. Metabolic Fate (Absorption, $\beta$-Oxidation and Deposition) of LongChain n-3 Fatty Acids Is Affected by Sex and by the Oil Source (Krill Oil or Fish Oil) in the Rat. Br. J. Nutr. 2015, 114 (05), 684-692.

(38) Tu, W. C.; Mühlhäusler, B. S.; Yelland, L. N.; Gibson, R. A. Correlations between Blood and Tissue Omega-3 LCPUFA Status Following Dietary ALA Intervention in Rats. Prostaglandins, Leukotrienes Essent. Fatty Acids 2013, 88 (1), 53-60.

(39) Salem, N. M.; Lin, Y. H.; Moriguchi, T.; Lim, S. Y.; Salem, N.; Hibbeln, J. R.; Hibbeln, J. R. Distribution of Omega-6 and Omega-3 
Polyunsaturated Fatty Acids in the Whole Rat Body and 25 Compartments. Prostaglandins, Leukotrienes Essent. Fatty Acids 2015, $100,13-20$

(40) Tian, Y.; Katsuki, A.; Romanazzi, D.; Miller, M. R.; Adams, S. L.; Miyashita, K.; Hosokawa, M. Docosapentaenoic Acid (22:5n-3) Downregulates MRNA Expression of Pro-Inflammatory Factors InLPS-Activated Murine Macrophage Like RAW264.7 Cells. J. Oleo Sci. 2017, 66, 1149.

(41) Serhan, C. N. Discovery of Specialized Pro-Resolving Mediators Marks the Dawn of Resolution Physiology and Pharmacology. Mol. Aspects Med. 2017, 58, 1.

(42) Leng, S.; Picchi, M. A.; Wu, G.; Belinsky, S. A. Dietary Nutrients Associated with Preservation of Lung Function in Hispanic and Non-Hispanic White Smokers from New Mexico, 2017; pp 1-11.

(43) Morin, C.; Hiram, R.; Rousseau, E.; Blier, P. U.; Fortin, S. Docosapentaenoic Acid Monoacylglyceride Reduces Inflammation and Vascular Remodeling in Experimental Pulmonary Hypertension. AJP Hear. Circ. Physiol. 2014, 307 (4), H574-H586.

(44) Guo, X.; Sinclair, A. J.; Kaur, G.; Li, D. Differential Effects of EPA, DPA and DHA on Cardio-Metabolic Risk Factors in High-Fat Diet Fed Mice. Prostaglandins, Leukotrienes Essent. Fatty Acids 2017, 1 DOI: 10.1016/j.plefa.2017.09.011.

(45) Nagao, K.; Nakamitsu, K.; Ishida, H.; Yoshinaga, K.; Nagai, T.; Mizobe, H.; Kojima, K.; Yanagita, T.; Beppu, F.; Gotoh, N. A Comparison of the Lipid-Lowering Effects of Four Different n-3 Highly Unsaturated Fatty Acids in HepG2 Cells. J. Oleo Sci. 2014, 63 (10), 979-985.

(46) Kaur, G.; Sinclair, A. A. J. A. A. J.; Cameron-Smith, D.; Barr, D. P.; Molero-Navajas, J. C.; Konstantopoulos, N. Docosapentaenoic Acid (22:5n-3) down-Regulates the Expression of Genes Involved in Fat Synthesis in Liver Cells. Prostaglandins, Leukotrienes Essent. Fatty Acids 2011, 85 (3-4), 155-161.

(47) Akiba, S.; Murata, T.; Kitatani, K.; Sato, T. Involvement of Lipoxygenase Pathway in Docosapentaenoic Acid-Induced Inhibition of Platelet Aggregation. Biol. Pharm. Bull. 2000, 23 (11), 1293-1297.

(48) Careaga, M. M.; Sprecher, H. Synthesis of Two Hydroxy Fatty Acids from 7,10,13,16,19-Docosapentaenoic Acid by Human Platelets. J. Biol. Chem. 1984, 259, 14413-14417.

(49) Poirier, Y.; Antonenkov, V. D.; Glumoff, T.; Hiltunen, J. K. Peroxisomal $\beta$-Oxidation-A Metabolic Pathway with Multiple Functions. Biochim. Biophys. Acta, Mol. Cell Res. 2006, 1763 (12), 1413-1426.

(50) Jakobsson, A.; Westerberg, R.; Jacobsson, A. Fatty Acid Elongases in Mammals: Their Regulation and Roles in Metabolism. Prog. Lipid Res. 2006, 45 (3), 237-249.

(51) Innis, S. M.; Dyer, R. A. Brain Astrocyte Synthesis of Docosahexaenoic Acid from N-3 Fatty Acids Is Limited at the Elongation of Docosapentaenoic Acid. J. Lipid Res. 2002, 43 (9), $1529-1536$.

(52) Morin, C.; Rousseau, É.; Fortin, S. Anti-Proliferative Effects of a New Docosapentaenoic Acid Monoacylglyceride in Colorectal Carcinoma Cells. Prostaglandins, Leukotrienes Essent. Fatty Acids 2013, 89 (4), 203-213.

(53) Kaur, G.; Begg, D. P.; Barr, D.; Garg, M.; Cameron-Smith, D.; Sinclair, A. J. Short-Term Docosapentaenoic Acid (22:5n-3) Supplementation Increases Tissue Docosapentaenoic Acid, DHA and EPA Concentrations in Rats. Br. J. Nutr. 2010, 103 (1), 32-37. (54) Christensen, E.; Woldseth, B.; Hagve, T. A.; Poll-The, B. T.; Wanders, R. J.; Sprecher, H.; Stokke, O.; Christophersen, B. O. Peroxisomal Beta-Oxidation of Polyunsaturated Long Chain Fatty Acids in Human Fibroblasts. The Polyunsaturated and the Saturated Long Chain Fatty Acids Are Retroconverted by the Same Acyl-CoA Oxidase. Scand. J. Clin. Lab. Invest. 1993, 215, 61-74.

(55) Tosi, F.; Sartori, F.; Guarini, P.; Olivieri, O.; Martinelli, N. Delta-5 and Delta-6 Desaturases: Crucial Enzymes in Polyunsaturated Fatty Acid-Related Pathways with Pleiotropic Influences in Health and Disease; Springer: Cham, 2014; pp 61-81.

(56) Delplanque, B.; Du, Q.; Leruyet, P.; Agnani, G.; Pages, N.; Gripois, D.; Ould-Hamouda, H.; Carayon, P.; Martin, J.-C. C. Brain
Docosahexaenoic Acid (DHA) Levels of Young Rats Are Related to Alpha-Linolenic Acid (ALA) Levels and Fat Matrix of the Diet: Impact of Dairy Fat. Ol., Corps Gras, Lipides 2011, 18 (6), 293-296.

(57) Jan, S.; Guillou, H.; D’Andrea, S.; Daval, S.; Bouriel, M.; Rioux, V.; Legrand, P. Myristic Acid Increases $\Delta 6$-Desaturase Activity in Cultured Rat Hepatocytes. Reprod., Nutr., Dev. 2004, 44 (2), 131140.

(58) Rioux, V.; Catheline, D.; Beauchamp, E.; Le Bloc 'h, J.; Pédrono, F.; Legrand, P. Substitution of Dietary Oleic Acid for Myristic Acid Increases the Tissue Storage of A-Linolenic Acid and the Concentration of Docosahexaenoic Acid in the Brain, Red Blood Cells and Plasma in the Rat. Animal 2008, 2 (4), 636-644.

(59) Leyton, J.; Drury, P. J.; Crawford, M. A. Differential Oxidation of Saturated and Unsaturated Fatty Acids in Vivo in the Rat. Br. J. Nutr. 1987, 57 (03), 383-393.

(60) Rolland, V.; Roseau, S.; Fromentin, G.; Nicolaidis, S.; Tomé, D.; Even, P. C. Body Weight, Body Composition, and Energy Metabolism in Lean and Obese Zucker Rats Fed Soybean Oil or Butter. Am. J. Clin. Nutr. 2002, 75 (1), 21-30.

(61) Park, H. G.; Engel, M. G.; Vogt-Lowell, K.; Lawrence, P.; Kothapalli, K. S.; Brenna, J. T. The Role of Fatty Acid Desaturase (FADS) Genes in Oleic Acid Metabolism: FADS1 $\Delta 7$ Desaturates 11-20:1 to 7,11-20:2. Prostaglandins, Leukotrienes Essent. Fatty Acids 2017, 128 (November 2017), 21-25.

(62) Delplanque, B.; Gibson, R.; Koletzko, B.; Lapillonne, A.; Strandvik, B. Lipid Quality in Infant Nutrition: Current Knowledge and Future Opportunities. J. Pediatr. Gastroenterol. Nutr. 2015, 61 (1), $8-17$. 